\title{
Conceptual Framework of Antecedents to Trends on Permanent Magnet Synchronous Generators for Wind Energy Conversion Systems
}

\author{
K. Padmanathan ${ }^{1, * \mathbb{D}}$, N. Kamalakannan ${ }^{1} \mathbb{D}$, P. Sanjeevikumar ${ }^{2} * \mathbb{C}$, F. Blaabjerg ${ }^{3}(\mathbb{D}$,
} J. B. Holm-Nielsen ${ }^{2}$, G. Uma ${ }^{4}$, R. Arul ${ }^{5}$, R. Rajesh ${ }^{6}{ }^{(D}$, A. Srinivasan ${ }^{7}$ and J. Baskaran ${ }^{8}$

1 Department of Electrical and Electronics Engineering, Agni College of Technology, Thalambur, Chennai, Tamil Nadu 600130, India

2 Center for Bioenergy and Green Engineering, Department of Energy Technology, Aalborg University, Esbjerg 6700, Denmark

3 Department of Energy Technology, Aalborg University, Aalborg, Denmark

4 Department of Electrical and Electronics Engineering, College of Engineering, Guindy, Anna University, Chennai, Tamilnadu 600025, India

5 School of Electrical Engineering, Vellore Institute of Technology, Chennai Campus, Chennai, Tamil Nadu 600127, India

6 Department of Automobile Engineering, Madras Institute of Technology, Anna University, Chennai, India

7 Department of Electrical and Electronics Engineering, Sri Krishna College of Technology, Coimbatore, Tamil Nadu 641042, India

8 Department of Electrical and Electronics Engineering, Adhiparasakthi Engineering College, Melmaruvathur, Tamil Nadu 603319, India

* Correspondence: padmanathanindia@gmail.com (K.P.); san@et.aau.dk (P.S.); Tel.: +45-7168-2084 (P.S.)

Received: 1 April 2019; Accepted: 3 July 2019; Published: 8 July 2019

\begin{abstract}
Wind Energy Conversion System (WECS) plays an inevitable role across the world. WECS consist of many components and equipment's such as turbines, hub assembly, yaw mechanism, electrical machines; power electronics based power conditioning units, protection devices, rotor, blades, main shaft, gear-box, mainframe, transmission systems and etc. These machinery and devices technologies have been developed on gradually and steadily. The electrical machine used to convert mechanical rotational energy into electrical energy is the core of any WECS. Many electrical machines (generator) has been used in WECS, among the generators the Permanent Magnet Synchronous Generators (PMSGs) have gained special focus, been connected with wind farms to become the most desirable due to its enhanced efficiency in power conversion from wind energy turbine. This article provides a review of literatures and highlights the updates, progresses, and revolutionary trends observed in WECS-based PMSGs. The study also compares the geared and direct-driven conversion systems. Further, the classifications of electrical machines that are utilized in WECS are also discussed. The literature review covers the analysis of design aspects by taking various topologies of PMSGs into consideration. In the final sections, the PMSGs are reviewed and compared for further investigations. This review article predominantly emphasizes the conceptual framework that shed insights on the research challenges present in conducting the proposed works such as analysis, suitability, design, and control of PMSGs for WECS.
\end{abstract}

Keywords: permanent magnet synchronous generators; wind energy conversion system; finite element analysis; soft computing techniques. 


\section{Introduction}

Energy is predominantly the driving factor of human life and the economy of global countries. Henceforth, the research investigation in this area is highly critical and the need lot of time to invest for in-depth study [1,2]. Due to the fast depletion of the natural conventional resources, sustainable alternative energy sources, for instance tidal wave, solar, wind, biogas/biomass and hydro energy, must be tap together for developmental activities. Therefore, there is currently a tremendous increase in the lookout for sustainable and alternative energy sources to generate electricity. Wind energy seems to be a promising and potential alternative renewable energy source with its enhanced sustainability and eco-friendly nature. According to 'Global Energy Outlook and the Increasing Role of India', in the year 2040, the electricity generation capacity of India will be equivalent to what is produced by today's European Union [3]. Figure 1 shows a summary of electricity generation by selected region and its electricity generation by 2040. The Global Wind Report (GWP, 2018) mentioned that the wind energy is one of the cheapest forms of electricity in a number of markets. Has it is a cost-effective option for countries which have ever-growing power demands and distribution challenges with centralized grid system [3].

\section{Growth to 2040}

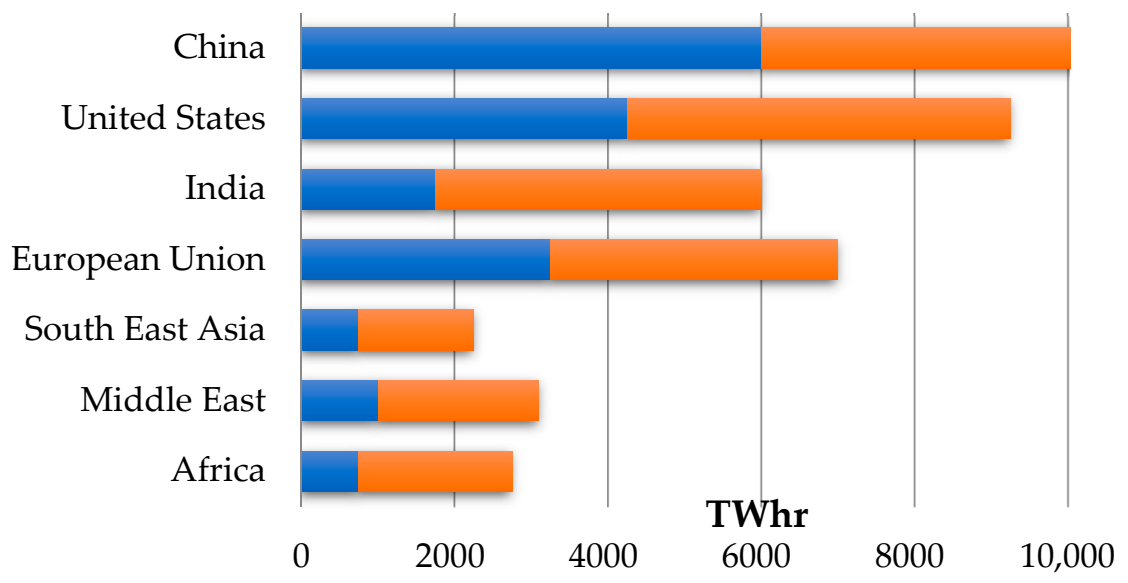

Figure 1. Electricity generation by selected region up to 2040. Source: International Energy Agency [3].

The Global Wind Energy Council (GWEC) suggested that wind energy sector (both the on-shore and off-shore) supplies $300 \mathrm{GW}$ of wind power capacity to come online by 2024 for global consumption. The global wind energy capacity increased with 51.3 GW in 2018. In spite of the fact, it is less than 2017 in about $4.0 \%$; it is still a good achievement in wind energy capacity addition. From the year 2014, there is a $50 \mathrm{GW}$ capacity addition occurring for every year though some markets behave differently. Thus, wind energy may contribute to electricity generation in India about 34,046 MW, which was 49.3) compared with all other renewable energy mix in the end of year 2018. By the year 2030, the wind power capacity is expected to generate $2300 \mathrm{GW}$ power, fulfilling $22 \%$ of the global electricity demands. The report published by Global Wind Energy Outlook 2018 [4] predicted the future of the wind energy industry until 2050. In 2018, 50,100 MW was added, which was lesser than that of the 2017's capacity addition 52,552 M). It is viewed in 2018 as the consecutive year with increased new installations accounting to $9.1 \%$, but this is lesser than the previous year's data i.e., $10.8 \%$ growth in 2017 . The global electricity demand met by $6 \%$ of the wind turbines installed in 2018. In Figure 2, the cumulative production based on wind sources for the year 2018 shown along with the newly added capacity for the year 2018 [4]. 


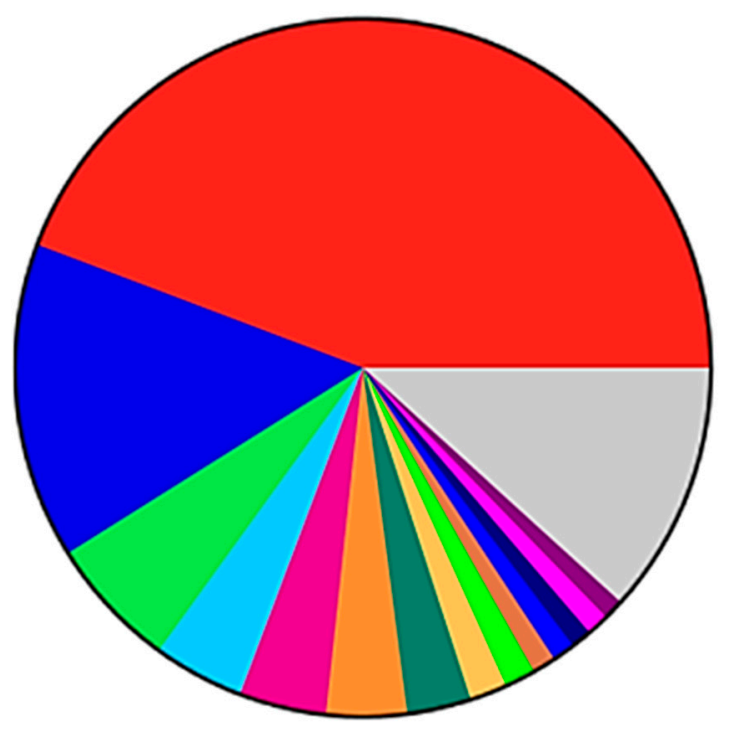

China: 23,000 MW (44.3\%)

United States: 7,618 MW (14.7\%)

Germany: 3,179 MW (6.1\%)

India: 2,191 MW (4.2\%)

United Kingdom: 2,098 MW (4.0\%)

Brazil: 1,939 MW (3.7\%)

France: $1,550 \mathrm{MW}(3.0 \%)$

Mexico: 929 MW (1.8\%)

Sweden: $716 \mathrm{MW}(1.4 \%)$

Canada: 566 MW (1.1\%)

Australia: 549 MW (1.1\%)

Belgium: $517 \mathrm{MW}(1.0 \%)$

Norway: 513 MW (1.0\%)

Turkey: $512 \mathrm{MW}(1.0 \%)$

Rest of the world: $6,091 \mathrm{MW}(11.7 \%)$

\section{a) New installed capacity (MW) by different country in 2018}

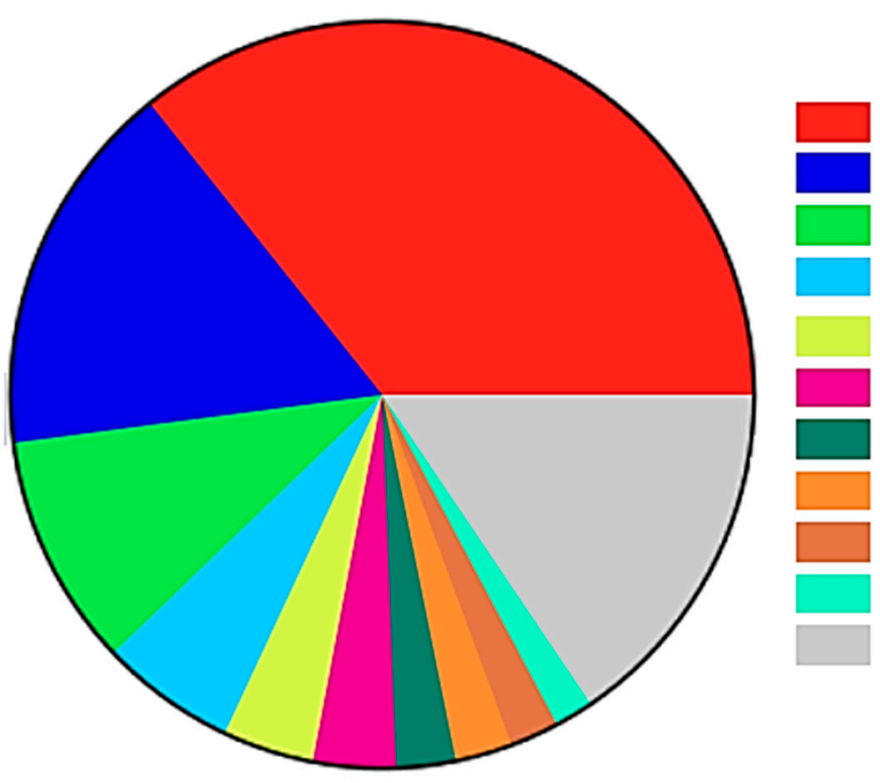

China: 211,392 MW (35.7\%)

United States: 96,665 MW (16.3\%)

Germany: 59,311 MW (10.0\%)

India: 35,129 MW (5.9\%)

Spain: 23,494 MW (4.0\%)

United Kingdom: 20,970 MW (3.5\%)

France: $15,309 \mathrm{MW}(2.6 \%)$

Brazil: 14,707 MW (2.5\%)

Canada: $12,816 \mathrm{MW}(2.2 \%)$

Italy: $9,958 \mathrm{MW}(1.7 \%)$

Rest of the world: $91,798 \mathrm{MW}(15.5 \%)$

\section{b) Installed capacity (MW) by different country in 2018}

Figure 2. Cumulative installed capacity of wind energy in the world end-of-year by 2018 and newly added capacity by different country in 2018 [4].

Figure 3 presents the overall baseline information of various settings, such as the new polices, moderate, and advanced scenarios. A global status report, published at the end of 2018, reported that global installed wind capacity was approximately $590 \mathrm{GW}$, which meant that Asia topped the regional market scale for the 9 th consecutive year. It accounts for a whopping $48 \%$ of the added capacity (a total that exceeds 235 GW by the end of the year 2019) followed by Europe (over 30\%), North America $(14 \%)$, and Latin America and the Caribbean (almost 6\%). In case of new installations, China retained the top position, though there was a contraction for two years. This was followed by US, Germany, $\mathrm{UK}$, and India in respective positions. 


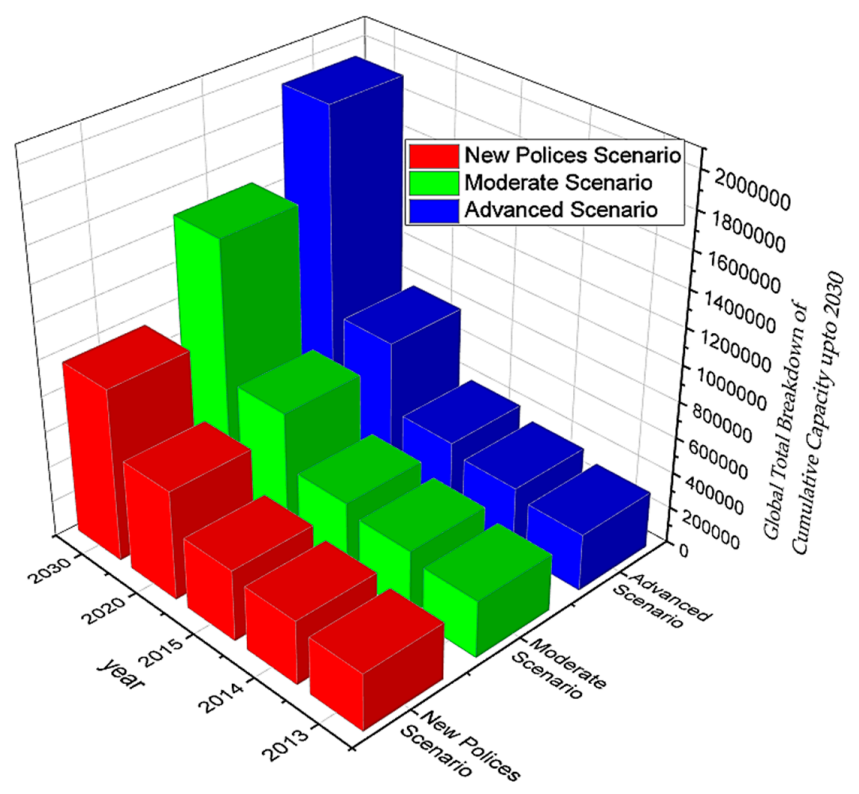

Figure 3. Global total breakdown of cumulative capacity up to 2030. Source: Global Wind Energy Outlook [4].

Globally, the energy demands were 282.5 GW and 318.105 GW in the years 2012 and 2013, respectively. This denotes that there was a strong market growth of more than $19 \%$ and $12.5 \%$ in the years 2012 and 2013, respectively. However, this seems to be the lowest growth rate i.e., 22\% and $21 \%$ of global electricity, when compared with annual average growth rate in the past decade. This is predicted to increase in the range of $8 \%-12 \%$ by the year 2020 . The wind penetration level increased up to $10 \%$ in the year 2016, in alignment with the guidelines for international agreements on environmental commitment. By the years 2030 to 2035, the predicted saturation level is about $1.9 \times 10^{9} \mathrm{~kW}$. The work by International Renewable Energy Agency (IRENA) titled 'Global energy transformation: A roadmap to 2050 (2019 edition)' inferred that by the year 2050, electricity would be the central energy carrier with growth up to $50 \%$ share from its current $20 \%$ share on final consumption. This would make the consumption of gross electricity double. The power demand across the globe (accounting to $86 \%$ ) will be met by renewable resources-based power. Overall, the final energy will have two-thirds of contribution from renewable energy [5]. According to the literature [6], the current study focuses on the hypothesis subjects such as Wind Energy Conversion System (WECS) history, transformation of Permanent Magnet Synchronous Generators (PMSG), Finite Element Method (FEM) leveraging, Soft Computing (SC) applications, and the upgradation of Computer Aided Design (CAD) which looks to be a novel perspective as the first step. Generally, the wind turbine is moved by the wind pressure as in step-like method, though its design is different. In wind energy production, low (cut-in) and abundant (cut-out) wind speeds are labelled as risk potentials. On the basis of size and design parameters, the risk potential of every turbine is decided. Generally, the electricity yield of a wind turbine ranges from 3 to $25 \mathrm{~m} / \mathrm{s}$ whereas high generation is examined once it crosses $10-15 \mathrm{~m} / \mathrm{s}$ values. Each turbine has cut-in as well as cut-out values that are contingent on size as well as design parameters [7]. Therefore, the wind turbine design plays an important role in energy production. Dai et al. (2019) stressed that, in recent years, the incorporation of wind turbine generators, such as Permanent Magnet Synchronous Generator (PMSG), and Doubly Fed Induction Generator (DFIG), in which the former is predominantly utilized in wind energy conversion system's has been commonly seen, since it is cost-effective, highly reliable, and has flexibility in control [7]. This paper aims to address the technical issues and fitness of WECS components and integration with electrical grid. Furthermore, it will explore the study of PMSG comprehensive comparisons with other topologies of generator. In addition, this paper will also shed insights on the gaps in research and areas to further enhance research, in the context of WECS. 


\section{A Brief Review of WECS}

In 2004 article discussed wind engineering in general and wind power meteorology with special reference to turbine and generator technology. Further, they discussed the economics, which are involved in this regard [1]. In a study conducted in 2007, the researchers stressed that the conversion of wind electricity is currently a green technology factor due to (1) structural design improvements, (2) design and manufacturing of blades, and (3) efficient power processing techniques, on the bases of power-electronics followed by new generator design, to achieve variable-speed operation [8]. In 2013, [9] discussed a list of possible changes in the methodology towards the implementation of utility-scale wind energy into the power grid and follow up in accordance to the updated research with their obtainable alleviation techniques. Figure 4 disseminates the growth in size of wind turbines since 1980 and for predicted future prospects. The scaling up of turbines to lower cost has been effective so far, but it is not clear that the trend can continue forever [10].

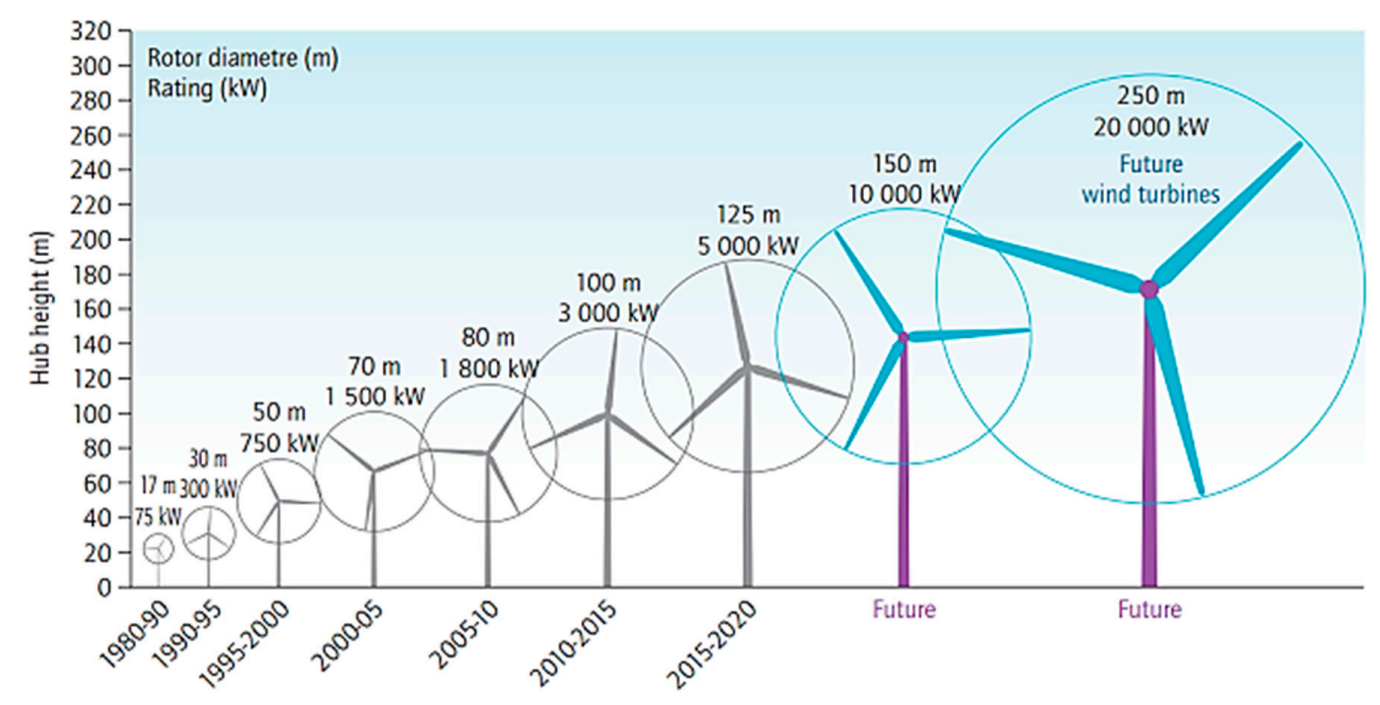

Source: adapted from EWEA, 2009.

Figure 4. Growth in size of wind turbines since 1980 and future prospects [10].

In 2012, [11] developed a 5 MW baseline design in deep wind concept with more than 150 deep Darrieus-type floating wind turbine systems. In this research article, the technology used in previous works employing various generator types and manufacturers of large power direct drive wind turbines were detailed. In Figure 4, the developments that occurred in the tower, blades, rotor diameter, power rating, and wind turbine hubs heights are illustrated. Amongst the available turbines, the $7.5 \mathrm{MW}$ turbine seems to be the most powerful one with a $126 \mathrm{~m}$ rotor diameter. The global wind report published in 2012 cited the new Alston Haliade 6 MW turbine to be the world's large turbine with a $150.8 \mathrm{~m}$ rotor diameter [12]. In the future, the next-generation wind turbines are predicted to hold $20,000 \mathrm{~kW}$ capacity with a $250 \mathrm{~m}$ rotor diameter.

In 2010, [13] investigated the power output density functions of different WECS for a variety of operating wind regimes with the help of a probabilistic approach. In 2007, [14] conducted a review of information regarding global wind energy scenarios, performance, and stability of wind turbines, sizes of wind turbine, wake effects, evaluation of wind resourced, site selection, wind turbine aerodynamics, and challenges faced in wind turbines followed by wind turbine technology. Which is inclusive of control system, design, loads, blade behavior, generators, transformers, and grid connection. In 2014, a review of notable technical as well as environmental impacts of wind farms, wind power resource assessment techniques, control strategies, and grid integration techniques, were conducted [15]. A comparative investigation was conducted using a Maximum Power Point Tracking (MPPT) control 
device in 2009 [16] between the optimized configurations of passive wind turbine generators with that of the active ones that operate at optimal wind power.

\section{Wind Turbine, Types, and Generator Technologies}

In the past decade, there has been a tremendous growth observed in wind turbine technologies and that have resulted in the development of new-age wind turbine concepts. With developments in wind generator systems, cost-effectiveness of the systems has become the new mandate. In a wind power generator system, there is a tower which supports rotating as well as the stationary parts. The nacelle that has the generator in it, power converter, grid side step-up transformer, monitoring and control equipment are present in the stationary part. In 2014, [17] developed a summary about compact and lightweight wind turbines along with the technical hindrances with special reference to Horizontal Axis Wind Turbines (HAWT). There are two broad categories of wind turbine technology at present; such has the HAWT and the Vertical Axis Wind Turbines (VAWT). The HAWT main rotor shaft rotates in alignment with the wind direction, whereas it is perpendicular to the ground, generator, transformer, converters, and other equipment in the case of the VAWT rotor shaft.

In HAWT, the nacelle is placed at the top position in the tower. The HAWT showcase better aerodynamic performance when compared to VAWT, due to which the former is largely deployed in large-sized offshore wind farms [17]. According to [18], there are approximately 8000 different components present in a typical wind turbine. This information is based on a RE power MM92 turbine with the blades' lengths being $45.3 \mathrm{~m}$ and the tower height being $100 \mathrm{~m}$.

Figure 5 shows the major components in a wind turbine and the share of the overall wind energy system parts cost. A direct-drive radial flux permanent magnet generator was checked for its suitability [19] to act as a drive-train runner. FEM software was used to test the generator fitness, based on structural design (or in other terms the stability of the air-gap present between the rotor and the stator) as per PMSG. So as to deduce the differences in flux density and force along the periphery of the rotor. In this study, the researchers used a simple analytical model. Further, 2D magneto-static simulations where also used to check the validity of the analytical model by making use of FEM software carried out [19].

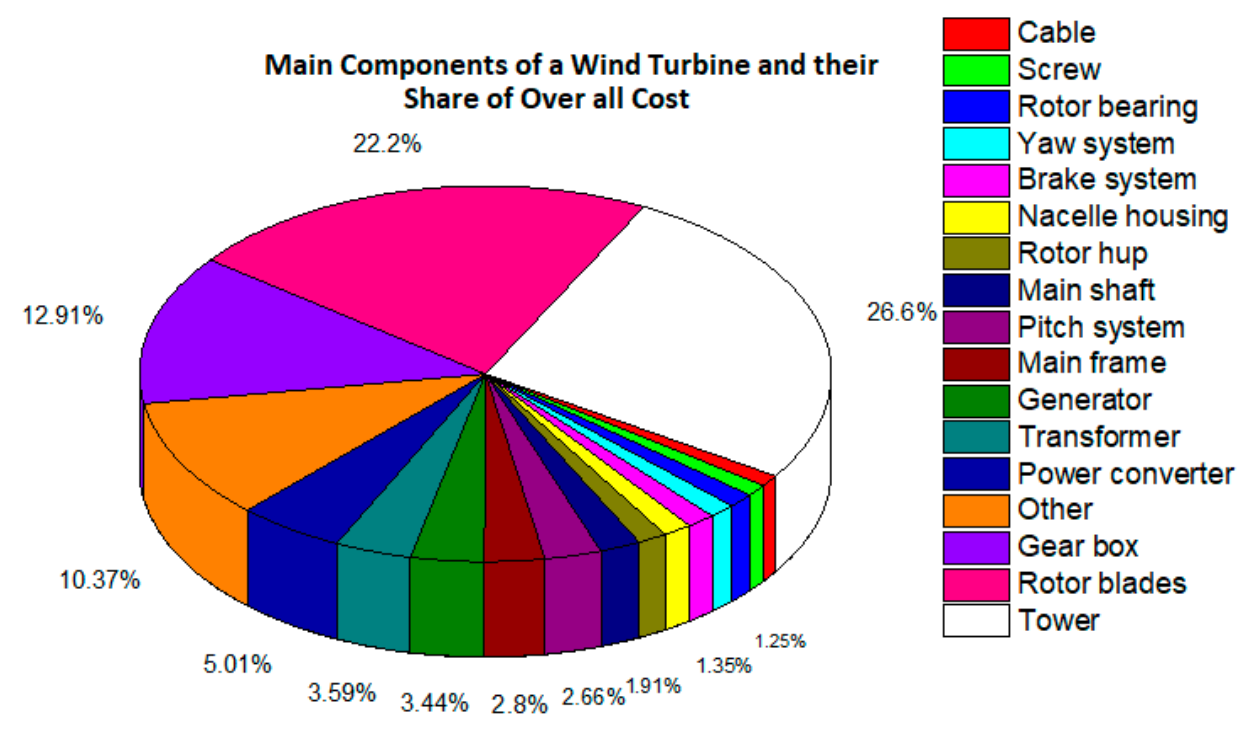

Figure 5. Main components of a wind turbine and their share of the overall cost [9].

According to the literature [20], the induction and synchronous generator models are general candidates used to convert wind energy to electrical energy. In 2009, [20] listed Danish wind power status and various topologies of other wind farm configurations. A classification was done by [21] to differentiate the wind turbine technology schemes. To be specific, the different categories 
are Full Rate Converter Wind Turbine (FRCWT), PMSG, Fixed Speed Wind Turbine-Squirrel Cage Induction Generator (FSWT-SCIG), Variable Speed Wind Turbine-Direct Drive Synchronous Generator (VSWT-DDSG), Squirrel Cage Induction Generator-Wind Turbine (SCIG-WT), Full Rate Converter Induction Generator (FRCIG), Direct Drive Synchronous Generator (DDSG), Variable Speed Wind Turbine-Doubly Fed Induction Generator (VSWT-DFIG), Squirrel Cage Induction Generator (SCIG), Fixed Speed Wind Turbine-Permanent Magnet Synchronous Generator (FSWT-PMSG), Fixed Speed Wind Turbine (FSWT), Doubly Fed Induction Generator (DFIG) and Variable Speed Wind Turbine-Full Rate Converter Induction Generator (VSWT-FRCIG) [21].

This segregation is done on the basis of power level, working principle, application type, and the usage in a number of commercial applications. The research and development in this area is still happening, and various novel configurations and advanced applications are in the testing stage. In 2006 compared different classification types and explained them in detail [22]. In general, based on the working principle, three electric generators are considered as main types: induction, synchronous machines. Parametric which are associated with magnetic anisotropy and permanent magnets. The study further mentioned that the parametric generators in most cases be called as doubly salient electric generators [22]. Since they are mostly equipped with doubly salient magnetic circuit structures. When classified according to the magnetic flux penetration, there are three types of permanent magnet generators present: transversal-flux, axial flux, and radial-flux machines [22].

Since the efficiency provided is better, most of the high-power direct-driven wind power applications prefer low-speed and high-torque PMSGs [23]. These are generally applied in a wide range of applications due to cost-effective Permanent Magnets (PM). According to the literature [23], Permanent Magnets can provide high-power densities, higher efficiency, and chances of compactness which eventually results in the reduction of turbine size. The advantages of Permanent Magnet generators are when it excludes the exciter field winding, slip rings, and brushes in association with the capability to self-excite making option, so as to achieve good efficiency as well as the high power factor. In a standalone system, the PMSG has overloading and full torque capability, a highly competitive feature, due to which it is unique when compared to other traditional electrical machines. The PMSG is capable of self-excitation, another exciting feature which makes it the best option for operating at higher power factors and efficiencies. Further, PM machines possess the ability of overloading and full torque at zero speed, as well as at lower speeds [24]. To be specific, the standalone power systems are utilized in the isolated areas. When compared with the traditional electrical machines, this is inevitably effective.

In 2009, [25] studied the prospective site matching of direct-drive wind turbine models on the basis of electromagnetic design optimization of PM generator systems. In this study, a three-phase radial-flux PM generator was developed with a back-to-back power convertor. The study had a total of 45 PM generator systems which were designed, optimized, and grouped as a collage of five-rated rotor speeds in the 10-30 rpm range and nine-power ratings in the range of $100 \mathrm{~kW}$ to $10 \mathrm{MW}$, respectively. Following this, the study also determined the rotor diameter and the rated wind speed of a direct-drive wind turbine under optimum PM generator on the basis of the maximum wind energy capture design principle. This study also calculated the Annual Energy Output (AEO) with the help of the Weibull density function. At last, at eight potential sites, the maximum AEO Per Cost (AEOPC) of the optimized wind generator systems was calculated along with yearly mean wind speeds ranging between 3 and $10 \mathrm{~m} / \mathrm{s}[25]$.

In 2008, [26] developed a concept of Permanent Magnet Generators Design. In this study, the researcher discussed the geared as well as direct-driven PM generators. Further, they also classified the direct-driven PM generators and the researchers dealt with various topologies of design aspects and unique nature in PM generators [26]. In 2012, [27] conducted a techno-economic evaluation of the basic assembly and magnetic topographies of the Salient Pole Synchronous Machine and Permanent Magnet Synchronous Machine. The study also provided the economic analyses of the machines that accompanied wind turbines. 


\section{Various Aspects of Comparison for PMSG's}

The design of electrical machines is important for any kind of applications. The basic design of an electrical machine involves certain procedures and analytical strategies. For calculation of magnetic circuit, electrical circuit, efficiency, insulation type, number of slots/poles combinations, winding dimensions, cogging torque analysis, control strategies, usage of materials, cost of products, thermal and structural design of electric machines, and manufacturing techniques etc. Finite Element Analysis (FEA) software can provide support for design and optimization tools to determine the best performance parameters. In 2008, [28] elaborately briefed and further used a deterministic global mathematical optimization which became a vital tool in the processes of design. Several mathematical models and optimization techniques could handle such problems associated with multi-faceted design. Figure 6 describes a complex range of ideas and significances of parameters for electrical machine design, analysis and characteristics studies, it has been simplified with partial adoption [28]. The studies conducted so far in this research areas, and various viewpoints have been established [28].

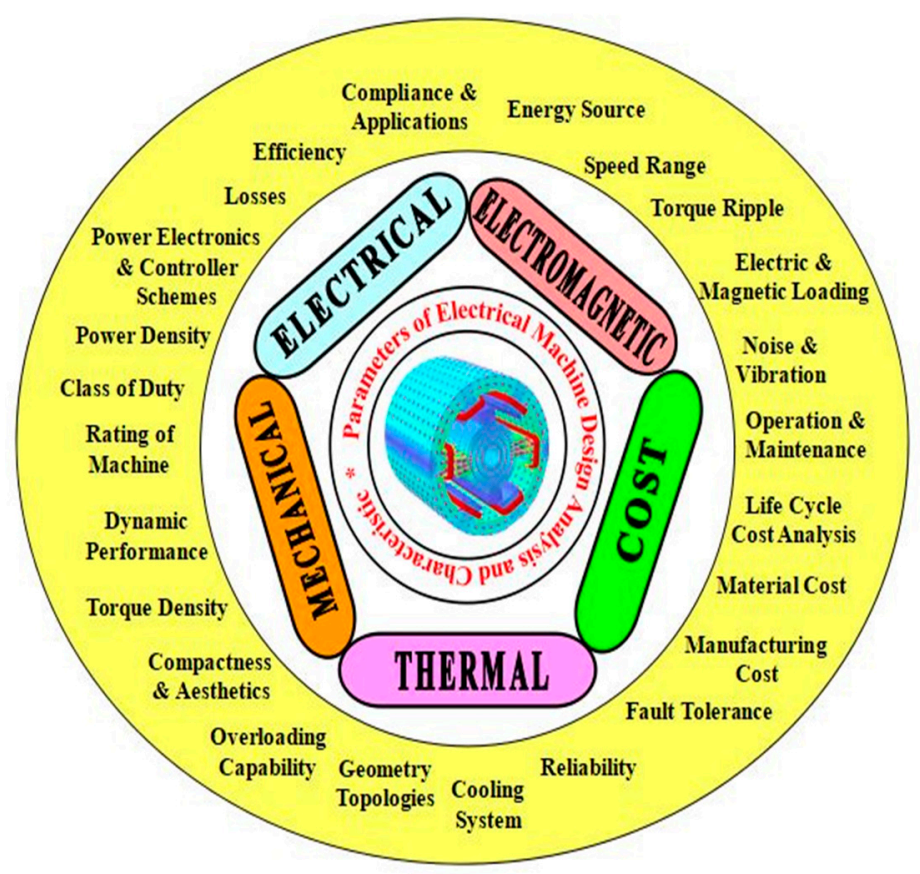

Figure 6. Electrical machine design parameters for analysis and characteristics studies.

In 2012, [29] conducted a general, as well as magnetic, analysis of various parameters, such as size, topology, voltage, magnetic field air-gap flux, weight, torque, losses, and efficiency between Permanent Magnet Synchronous Machines (PMSMs) and Conventional Salient Pole Synchronous Machine (CSPSMs) with the help of FEM. Figure 7, the weights of active material and costs are compared, and analyzed. Based on the comparison, it is observed that the total weight of the active material in the PMSM is reduced by $6.55 \%$ more than the conventional salient pole machine. In Figure 8 , the losses at full load are presented [27].

With the same output power generated by the Permanent Magnet used in the machine, there will be reduction in machine weight which eventually becomes lighter to produce and so it increases the efficiency. Once the investigation was complete, it was observed that the CSPSM expressed less efficiency when compared to PMSM's. Further, when it comes to enhancement of magnet and semi-conductor expertise, the PMSMs reaped a cost-based benefit. Therefore, at the time of designing electrical machines, it is advised to follow their strategy in terms of machine efficiency and efficient use of energy [29]. 


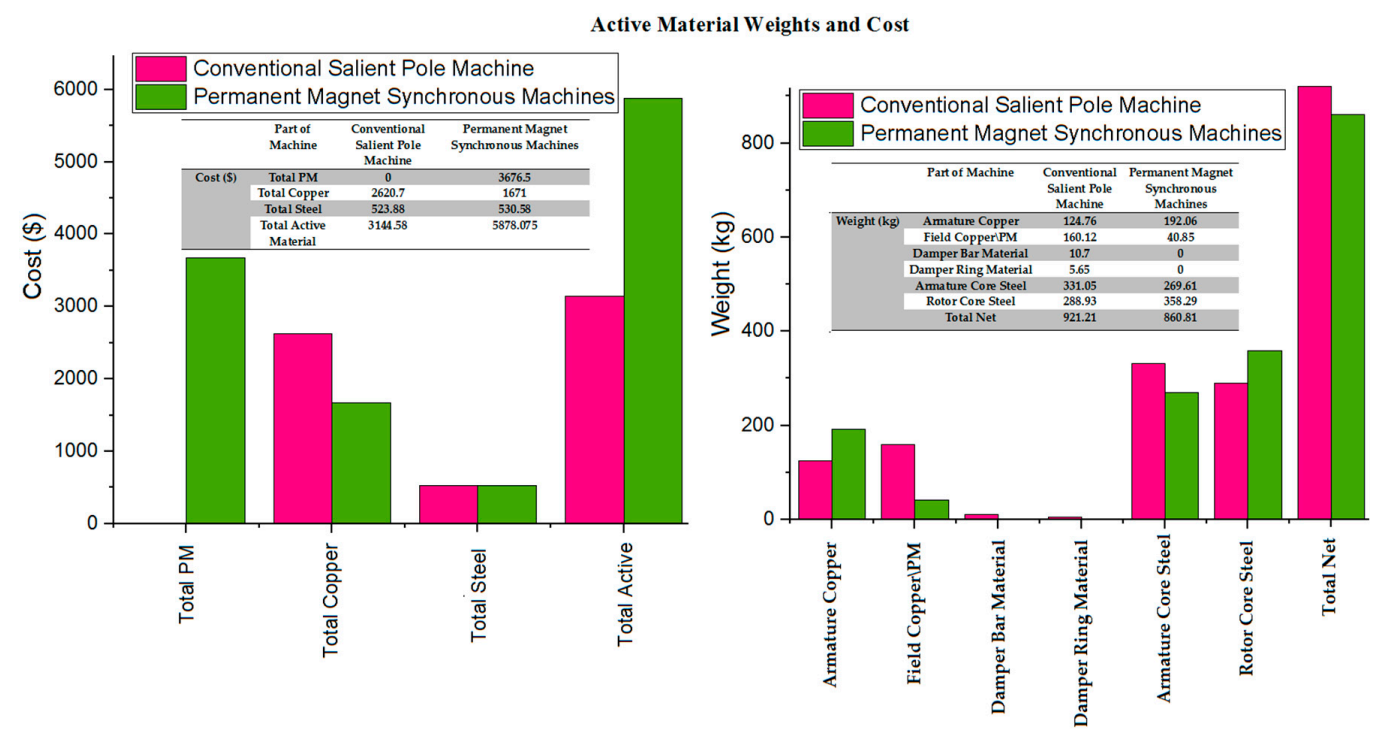

Figure 7. Active material weights and Cost comparison of PMSM and conventional machines [29].

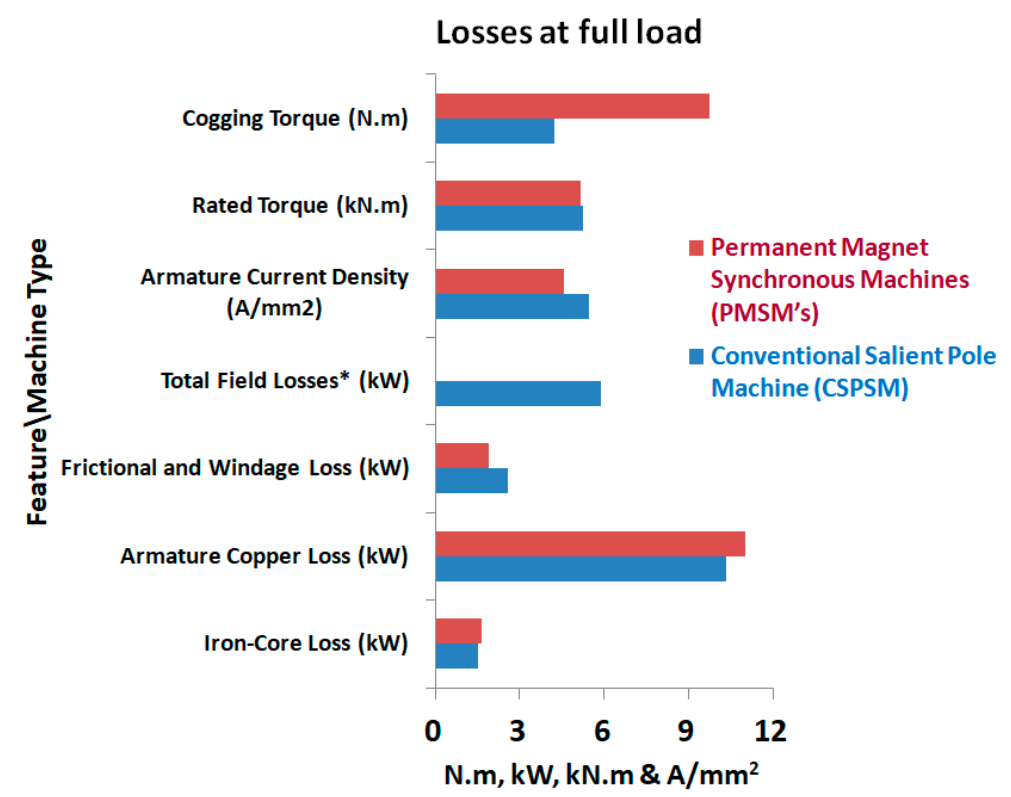

Figure 8. Losses comparison for PMSM and conventional machines at full load conditions [27].

A seven type of systems such as variable-speed constant frequency (VSCF) wind generator system, PMSGDD, PMSG1G, PMSG3G, DFIG3G, DFIG1G, EESG_DD (Electricity-Excited Synchronous Generator with direct-driven), and SCIG_3G (Squirrel Cage Induction Generator with three-stage gearbox) has been compared. In this comparative study, the researcher made optimization designs for different wind generator systems in the range of $0.75,1.5,3.0,5.0$, and $10 \mathrm{MW}[30,31]$. The results inferred that the PMSG_DD was cost-effective when compared to EESG_DD systems due to the cost incurred in lower generator system and enhanced Annual Energy Production (AEP) per cost. When there is an increase in wind turbine, the cost spent on direct-drive wind generator seems to be reduced. However, when there is an increase in the rated power, there is an enhanced performance exhibited by the PMSG_DD system when compared to the EESG_DD system.

Following is the description for a single-stage gearbox drive train concept. Due to the low-cost generator system and high AEP per cost, the focus shifted to the DFIG_1G system which seems to be the best alternative. Further, when viewed from AEP per cost perspective, the DFIG_1G system seems to be the most cost-effective and is close to $1.5 \mathrm{MW}$. Following is the concept behind three-stage behavior 
drive-train. Due to the least cost generator system and high AEP per cost, the DFIG_3G system was considered as the best solution among other three wind generator systems. Additionally, in terms of AEP per cost aspect, more emphasis is given to the PMSG_3G system compared to the SCIG_3G system [31]. Figure 9 compares all five various wind generator systems of respective manufacturers in a wide range of aspects.

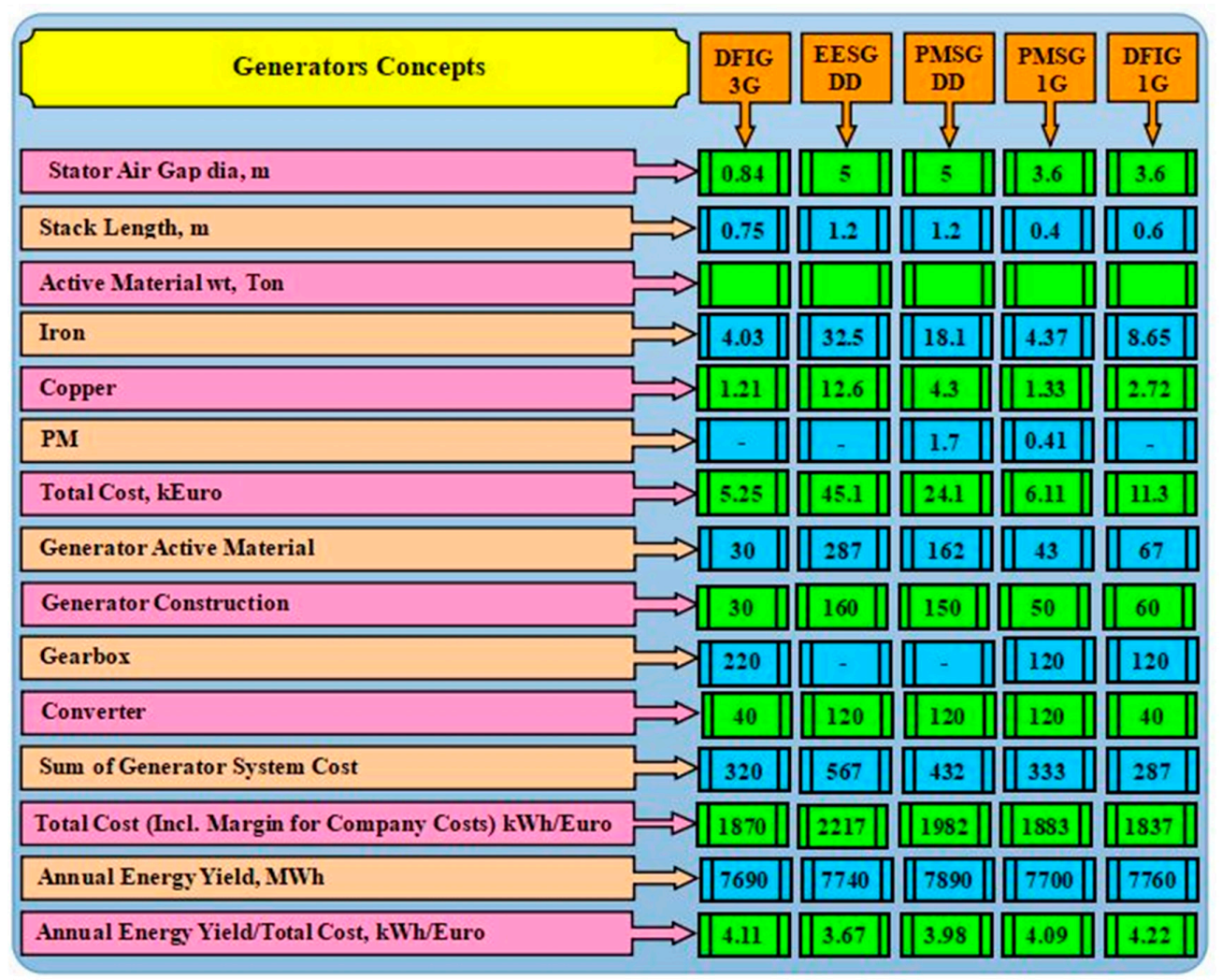

Figure 9. Comparison of five different wind generator systems [31].

When compared in terms of cost between a multi-hybrid PM wind generator system loaded in single-stage behavior and the direct-drive concept, the former seems to be cost-effective. When there is an increase in the size of the wind turbine, then the adoption of gear ratios may also widely vary. Based on the rated power levels, the optimum gear ratio may vary from 4:1 to 10:1. In the case of larger power ratings, the literature [17] suggests making use of higher gear ratios would be better performance. In 2014 mentioned that PMSGs are predominantly employed by giants such as the manufactures as follows GE energy, Vestas, Siemens, Gamesa and Goldwind. The stator of the PMSG is wound where the rotor is present with the PM pole system and may possess salient cylindrical poles. At most of the time, the low-speed synchronous machines project the salient-poly type with predominantly numerous poles. One can develop a direct drive system based on a synchronous generator with an ideal number of poles (a multi-pole PMSG). Some common types are transversal flux machine, axial flux machine, and the radial flux machine. The PMSG machine expressed highest the efficiency in an induction machine since the excitation was supplied excluding any energy flow. However, it is difficult to manufacture the PMs, whereas its inventory is cost-consuming too [17].

The long-term-unaddressed issue comes with the mandate to maintain the rotor temperature less than the magnet's threshold temperature. This may further be influenced by the magnetic material's Curie point and the binding material's thermal criterion in the case of power metallurgy composites. In turn, the synchronous process generates the issue according to the start-up, synchronization, and voltage regulation [32]. In 2011, Sandra Eriksson et al. performed an excellent comparison of direct-driven PMSGs. A total of six different-range generators were compared among each other [33]. 
Figure 10 clearly depicts the considerations of various factors with respect to the fixed and variable parameters for different ranges of generators.

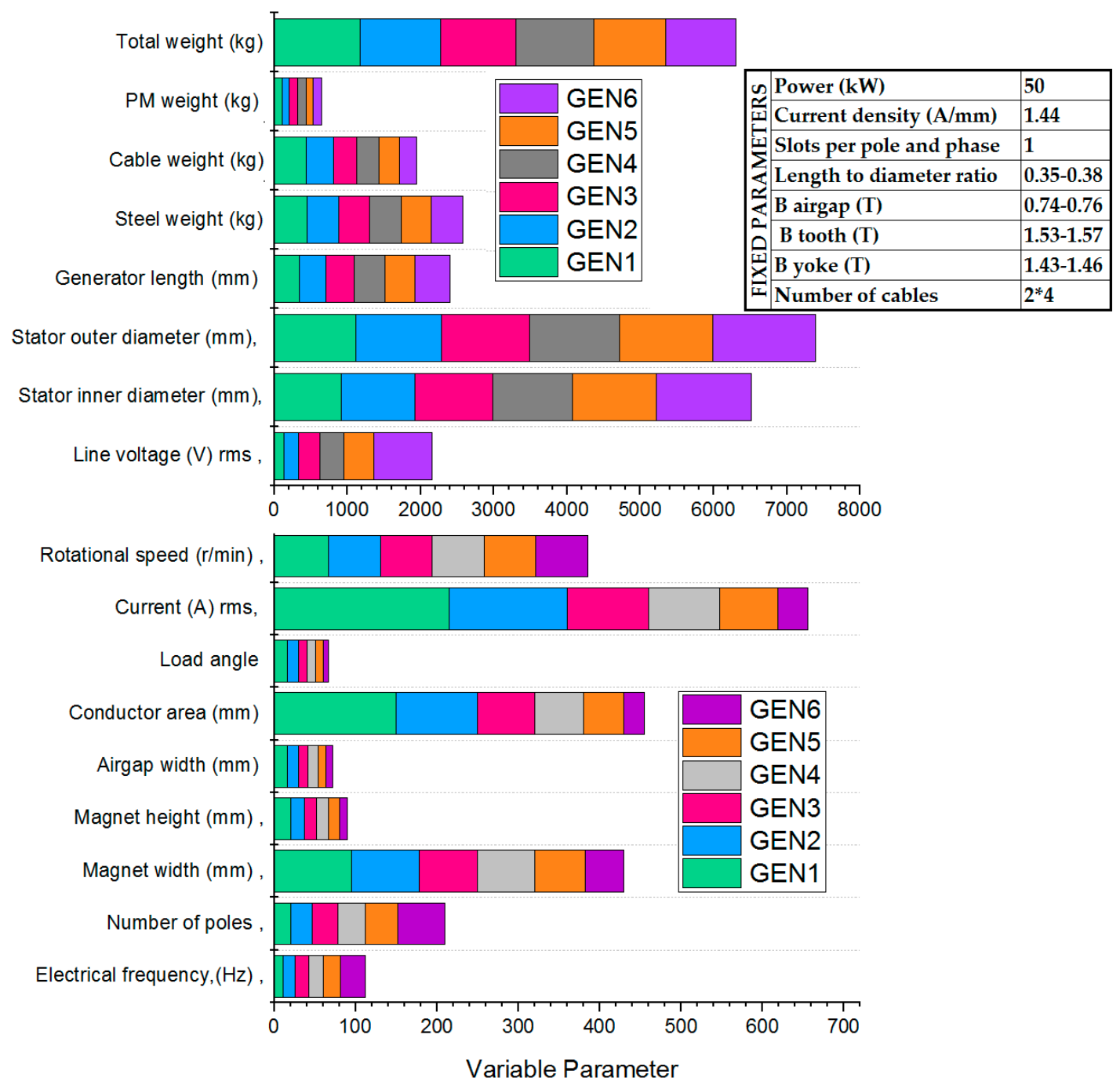

Figure 10. Characteristics of rated speed and power for stationary simulations [33].

In 2013, [34] compared three configurations such as gearless-drive Permanent magnet induction generator PMIG-WECS, gearless-drive PMSG, geared-drive squirrel-cage induction generator (SCIG), and in the index every system was allocated with a number such as 1, 2, and 3 to position itself in the rank in accordance to other two systems. According to Table 1, the geared-SCIG system seems to be prominent in $61.5 \%$ of the indexes, while at the same time $38.5 \%$ of indices where dominated by the gearless-PMSG system. There was a $60 \%$ similarity in advantages between gearless-PMIG and gearless-PMSG. Therefore, the geared-SCIG system exists in alignment with the number of indexes. However, there is a domination of gearless-PMSG in the three top priority indexes such as generation efficiency, Operation \& Maintenance (O\&M) cost, and the duration of failure behavior. Further, there was a domination of geared-SCIG in the four top priority indexes such as kWh production at low speed, frequency of failure, generator O\&M cost, and capital cost. In order to achieve the results with best accuracy, the weight of an index should be considered as per the order. Among the different configurations considered for the study, the results concluded that the gearless-drive PMSG-based and geared-drive SCIG-based systems seem to be the most desirable solutions. From Table 1, it is identified that the gear less PMSG is the only machine, which has the best option in efficiency, as there is no gearbox and copper loss [34]. 
Table 1. Comparison of Geared-Drive Squirrel Cage Induction Generator (SCIG), Gearless-Drive Permanent Magnet Synchronous Generator (PMSG), and Gearless-Drive PMIG-Wind Energy Conversion System (WECS) configurations [34].

\begin{tabular}{|c|c|c|c|c|c|c|c|}
\hline $\begin{array}{l}\text { Order of } \\
\text { Index }\end{array}$ & $\begin{array}{l}\text { Index } \\
\text { Name }\end{array}$ & Details of Index & $\begin{array}{l}\text { Geared } \\
\text { SCIG }\end{array}$ & $\begin{array}{l}\text { Gearless } \\
\text { PMSG }\end{array}$ & $\begin{array}{l}\text { Gearless } \\
\text { PMIG }\end{array}$ & Best Options & Comments and Justifications \\
\hline 1 & Reliability & Duration of failure & 2 & 1 & 1 & PMSG and PMIG & No \\
\hline 2 & & Frequency of failure & 1 & 2 & 2 & SCIG & $\begin{array}{l}\text { There may be high failure rate present in direct-drive due to } \\
\text { the fact that there is a direct transfer of wind rotor fluctuation } \\
\text { to generator and power electronics }\end{array}$ \\
\hline 3 & O\&M cost & Gearbox & 2 & 1 & 1 & PMSG and PMIG & Absence of gearbox in direct-drive turbines \\
\hline 4 & & Generator & 1 & 2 & 2 & SCIG & $\begin{array}{l}\text { Generator failures are costly in direct-drive turbines. In } \\
\text { direct-drive turbines, the generator failures prove to be } \\
\text { cost-consuming processes }\end{array}$ \\
\hline 5 & $\begin{array}{l}\mathrm{kWh} \\
\text { production }\end{array}$ & $\begin{array}{l}\text { Affected by cut-in, } \\
\text { rated and cut-out } \\
\text { wind speed }\end{array}$ & 1 & 2 & 2 & SCIG & $\begin{array}{l}\text { There is a negative association present between the cogging } \\
\text { torque in PM generators and the cut-in speed of the turbine. } \\
\text { This eventually is reflected in the generation of } \mathrm{kWh}\end{array}$ \\
\hline 6 & $\begin{array}{c}\text { Capital } \\
\text { cost }\end{array}$ & $\begin{array}{l}\text { Cost of generator and } \\
\text { gearbox (if any) }\end{array}$ & 1 & 3 & 2 & SCIG & $\begin{array}{l}\text { Due to the magnets, the PM machines are high } \\
\text { cost-consuming }\end{array}$ \\
\hline 7 & Efficiency & $\begin{array}{l}\text { Accounts for gearbox } \\
\text { and generator loss }\end{array}$ & 3 & 1 & 2 & PMSG & $\begin{array}{l}\text { There is neither gearbox nor rotor copper losses occur in } \\
\text { gearless PMSG and it also works at high PF }\end{array}$ \\
\hline 8 & $\begin{array}{l}\text { Excitation } \\
\text { Requirements }\end{array}$ & Reactive power source & 3 & 1 & 2 & PMSG & $\begin{array}{l}\text { Full external excitation is observed in SCIG whereas it is } \\
\text { partial in PMIG. In case of PMSG, it is completely } \\
\text { internally-excited }\end{array}$ \\
\hline 9 & $\begin{array}{l}\text { Magnet } \\
\text { problems }\end{array}$ & $\begin{array}{l}\text { Demagnetization and } \\
\text { future availability }\end{array}$ & 1 & 2 & 2 & SCIG & There are no magnets in SCIG \\
\hline 10 & $\begin{array}{l}\text { Control } \\
\text { simplicity }\end{array}$ & & 1 & 2 & 3 & SCIG & $\begin{array}{l}\text { In spite of SCIG being simple in control, the fixed magnet } \\
\text { excitation in PM machines complicates the controls }\end{array}$ \\
\hline 11 & $\begin{array}{l}\text { Construction } \\
\text { simplicity }\end{array}$ & $\begin{array}{l}\text { Number of poles, } \\
\text { diameter size, and } \\
\text { rotor design }\end{array}$ & 1 & 2 & 3 & SCIG & $\begin{array}{l}\text { Due to the multi-pole development, the direct-drive PMSG is } \\
\text { large and heavy. Due to double-rotor design, the PMIG seems } \\
\text { to be complicated }\end{array}$ \\
\hline 12 & Noise level & Drive train & 2 & 1 & 1 & PMSG and PMIG & There is no gearbox noise in PMSG and PMIG \\
\hline 13 & Generator & & 1 & 2 & 2 & SCIG & There is no notable cogging torque is SCIG \\
\hline
\end{tabular}


In 2010, [35] with the field-circuit method for rapid calculation of load characteristics for stand-alone PM synchronous generators (PMSGs) that were developed with various rotor structures. The study results were compared with load characteristic calculations and results. The field-circuit method was defined, and utilized to determine the load characteristics of PMSGs with surface-mounted, inset or interior mounted permanent magnets and with inner or outer rotors [35]. In a comparative study conducted 2013, two PM generator types such as radial flux PM (RFPMG) and axial flux PM (AFPMG) generators were compared. To compare the generator performance during mechanical energy storage, the study measured the output powers of both RFPMG and AFPMG [36]. Results shown in Figures 11 and 12, concludes that there was a better performance exhibited by RFPMG when the machine's electrical parameters were in very similar condition and in relatively small power applications. It was inferring that the RFPMG has fewer copper, core, and rotor losses with respect to the varying generator and wind speed when compared to AFPMG [36].

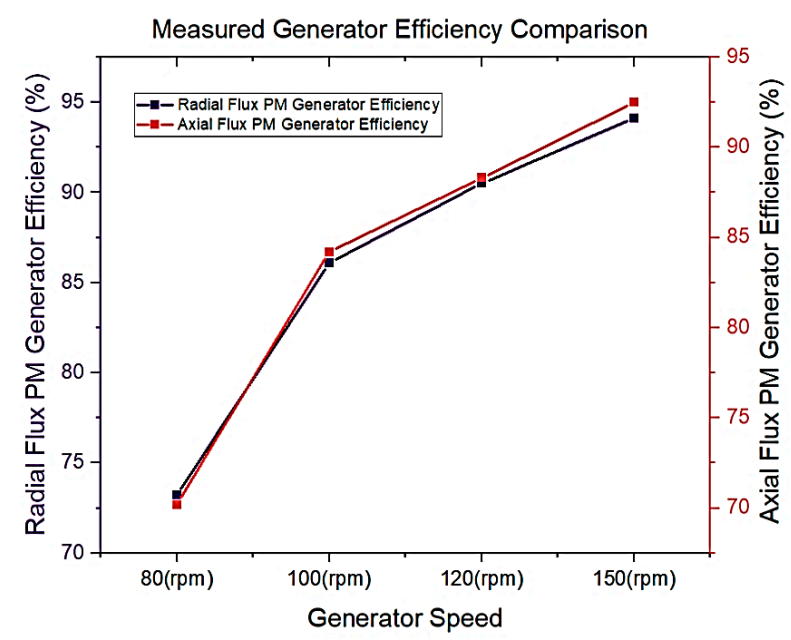

Figure 11. Measured generator efficiency comparison [34].

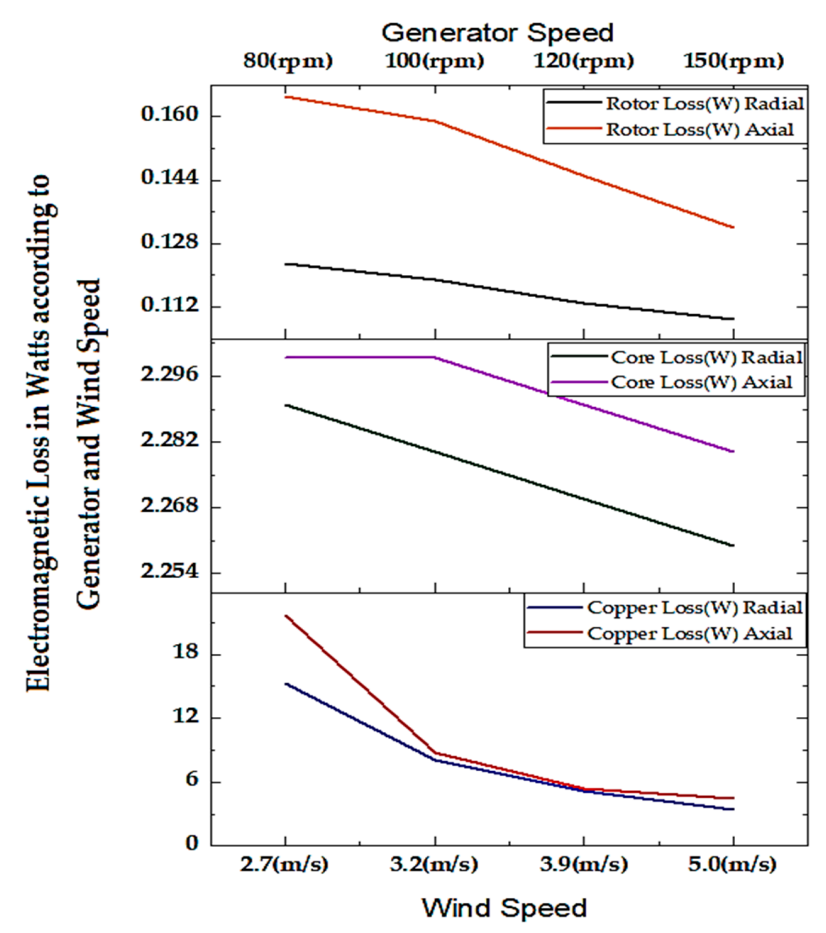

Figure 12. Electromagnetic loss according to generator speed [33]. R: Radial Flux PM Generator, A: Axial Flux PM Generator. 


\section{Different Design Perspectives}

Designing PMSG has several challenges, which make it complicated when compared to conventional machine design procedure. The combination called 'Slot and Pole' poses various other challenges, which include reducing eddy current losses and cogging on permanent magnets. In 2013, [37] a technique was proposed to improve the air-power gap apparently transferred under the constraint of tangential stress using analytical optimization algorithms. The processes of optimization have been optimized for expressions that are relevant for the design of main variables, external derivations, and operational restrictions for the formulation of mathematical derivations.

In general, terms, during PMSG design, the optimum design includes various mandatory requisites, which are to improve profitability, and mitigate utilization of material to reduce cost and weight [38]. In addition, the design considerations should also take into account availability, high reliability, and low serviceability and maintainability for TC Ia that is wind class [38]. Furthermore, the utilization of gearless or semi-geared drive machines improves efficiency and reliability of wind power generators. Additionally, such requisites are associated characterization of compactness in terms of weight and dimensions. In addition, during the design of PMSG, the mechanical forces and voltage waveforms are quite imperative in several applications [38].

The design of machines is generally concerned with the electric and magnetic circuits; however, there are several losses which are measured using empirical equations [39]. In 2011, [39] explored the various design aspects concerned with the radial and axial field of synchronous machines with permanent magnets. In addition, the analysis of three fractional-slot and concentrated winding permanent magnet synchronous machine topologies are suited especially for specific applications [39]. According to a study [40], which explored the performance of wind power generators fitted with external permanent magnet rotors. The authors analyzed the FEM and electromagnetic results that examined the turbine characteristics and variations of the nominal wind speeds; various systematic methods were employed in previous research. For the calculation of the electrical characteristics, such as synchronous inductance, Electromotive force (EMF) constant, and phase resistance, an electromagnetic analytical and magnetic field distribution method was applied. In this study, a d-q model coordinate transformation theorem was employed for the analysis of performances. In addition, FEMs and curve fitting are used for the analysis of core losses [40]. Furthermore, a dissertation [41] presented a transformation theorem that developed a technique for the optimization and design of machines mounted with Surface Mount Permanent Magnet (SMPM), as impacted by mechanical loads, energy source, thermal effects, and state-of-the-art developments in manufacturing and material capabilities. A method was proposed for the design and development of cage rotor induction machines that can be optimized for better performance. Both genetic algorithm GA and particle swarm optimization (PSO) were used for optimization of the machines. Different integrated methods were applied and the Electromagnetic-Thermo-Mechanical method was used for the fabrication of Surface Mount Permanent Magnet (SMPM) machines [41]. An iron-less brushless permanent magnet machine was proposed and designed in 2013 [42] for the design and optimization of generator applications. The proposed approach constituted a dimensioning technique that involves comprehensive geometric techniques; both electrical and magnetic methods were used followed by the use of a detailed 3-D finite element (FE). In addition, the machine configurations used were both circular and rectangular designs, and were compared against each other. Furthermore, the performance of ironless stator designs configurations and the effectiveness of materials used were compared [42]. Tangential magnetic flux and stator concentric windings were incorporated in wind power generators in 2009 [43] with the rotation frequencies of 75-300 rpm. The parameters associated with the developed generators were depicted in the research. The intention of the previous research was to analyze the working of synchronous generators fitted with permanent magnets, which is in line with the concept of mitigating the problem of magnetic field distribution that was studied separately using FEM. During the development of such models, as given below in Tables 2 and 3 the following parameters to acquire synchronous machines should be considered and varied: 
In addition, the following parameters should be considered for mathematical simulation.

Table 2. Parameters need to be considered for acquiring synchronous machines [43].

\begin{tabular}{cl}
\hline S.No & \multicolumn{1}{c}{ Parameters } \\
\hline 1 & Rated project parameters such as voltage, power, rotation frequency, and power coefficient \\
\hline 2 & Basic sizes such as active length and stator boring diameter \\
\hline 3 & $\begin{array}{l}\text { Machine's winding parameters such as phase number, number of poles, number of slots and turns, } \\
\text { and parallel branches of stator winding }\end{array}$ \\
\hline 4 & Magnet's geometrical sizes and the Air gap between stator and rotor \\
\hline
\end{tabular}

Table 3. Parameters need to be considered for mathematical simulation.

\begin{tabular}{cl}
\hline S.No & \multicolumn{1}{c}{ Parameters } \\
\hline 1 & Efficiency and distribution of losses in a generator \\
\hline 2 & Diagram of magnets and reserve coefficient over magnets \\
\hline 3 & Static overloading in generators \\
\hline 4 & Inductive scattering resistances along longitudinal and cross axes \\
\hline 5 & Generator's parameters under loading and short circuit \\
\hline 6 & Generator's performance (external and no load) \\
\hline
\end{tabular}

In 2012, [44] examined and designed PMSG using FEM simulation software that involves low speed three phase generators associated with external rotors. The aim of the research paper was to obtain sinusoidal voltages that are induced in stator windings which are espoused magnetization and arrangement path of permanent magnets within the rotor structure [44]. Again in 2012 [45], used the multi-physics approach for the design and development of a 10-MW doubly fed induction generator (DFIG). The optimal design and analyses were considered for the operation of direct drive of wind turbines with a conversion that has reduced size. In 2005, [45] performed a study that comprised of PMSGs that were used in wind power generation systems that are small. The output voltage was examined using FEM wherein both no-load and load conditions were considered. The influence of shapes and magnetic dimensions was examined. The previous research is a novel study wherein the outcomes of FEM were analyzed that revealed the PMSG's cogging torque frequency was influenced by number of poles and stator slots. However, the performance was influenced by factors such as magnet dimension, air-gap length, and cogging torque magnitude [46]. Research conducted by [47] (2008) depicted the design, prototyping, and analysis of relatively small and cheap axial-flux three-phase coreless permanent magnet generator. In the previous research, the FEM approach was used for the measurement of equivalent circuit inductances. In addition, the end winding inductance calculation and equivalent resistance of eddy-current loss where calculated using traditional methods. In 2002, [48] proposed a method for performance improvement using soft magnetic composite inter poles in drive permanent magnet machines. Several factors such as suitable pole arc shapes, magnet dimensions' influence, material usage efficiency, and labor costs where considered. In 2011, [49] examined the design considerations of double rotor radial flux permanent-magnet wind generators in terms of the mechanical and electromagnetic non-overlap air-cored (ironless) stator windings. The developed model was examined using finite-element analysis. The results of the analysis revealed that the electromagnetic design determines the mass, cost, rotor yoke dimensions, and leakage flux paths. In 2012, [50] examined the axial flux PM generator performances using wind turbine characteristics and electromagnetic field. The analytical approach could mitigate the analysis time required when compared with the FEM that is three-dimensional, which could use for the calculation of performances in the preliminary design phase. In 2010, [51] proposed and developed an optimal design high-speed DC generation system that uses a slot-less PM machine. In the previous research, the researcher used 
soft magnetic composite (SMC) stator yoke and a controlled rectified fitted to the stator winding [51]. In [52] (1997) further examined the multi pole PMSG with the radial field. PMSG machines have been used as direct-coupled grid-connected generators with ratings between $100 \mathrm{KW}$ and $1 \mathrm{MW}$. However, the previous research revealed that the poles that are between 100 and 300 are found to render better performance in terms of efficiency and reactance. The stator and rotor section design present the suitable pole and power number. Standard ferrite magnet wedges are used in the rotor sections. The stator sections however are made up of $\mathrm{E}$ cores with a single rectangular coil in each core. The researcher also developed a lumped-parameter magnetic model that permits the calculation of machine parameters in a rapid manner [52]. In [53] (2007) examined the direct-coupled an Axial Flux PMSG (AFPMSG) that is appropriate for a wind turbine system. Furthermore, the researcher used horizontal-axis and vertical-axis wind turbine generator systems. FEM analysis was undertaken for the analysis of the AFPMSG magnetic flux density distribution. The results analyzed were compared with the proposed machine configuration wherein the voltage from the output line was found to be of sinusoidal pattern. AFPMSG design feasibility was confirmed using a prototype generator [53]. In 2010, [54] further displayed an Axial-Flux Permanent-Magnet Generator for Induction Heating Gensets whereas $([55], 1997)$ and $([56], 1994)$ proposed a straightforward approach for the design of brushless permanent-magnet machines; the results are supported by several analytical results. The main difference between sine wave and square wave motors are detailed and described in terms of EMF, self-inductance, flux density and so on. A stage by stage method is involved with the design of computer-aided systems which are elaborated in detail. The previous research detailed the information such as torque, shape, magnet poles and phases, slots, poles, teeth, energy and co-energy, magnetic circuit concepts, yokes, basic relationships, magnetic materials, flux linkage and inductance, influence of stator slots, tooth flux, back-EMF, need for the field analysis based design FEM, cogging torque, series and parallel connections, and loss modeling [56]. Though machines achieve infinitely, the core of the machine that operates under unsaturated conditions and deep rectangular slots are not appropriate and not suitable for the design of today electrical machines with non-linear materials. The machine's performance should be predicted with great accuracy to solve non-linear equations which is expressed in terms of the Magnetic vector potential. The irregular machine geometry confirmation makes the analytic method configuration challenging. Hence, there is a need to use appropriate field computation, and modeling techniques utilizing electromagnetic fields such as the energy minimization. Includes, differential/integral functions, variational method, discretization, shape functions, stiffness matrix, 1D and 2D planar and axial symmetry problem and computation of electric and magnetic field intensities, capacitance and inductance, force, torque, and energy for basic configurations of electrical machines [57].

In Figure 13, various electromagnetic analytical methods are illustrated. Every method contains a set of advantages as well as disadvantages. In this scenario, the finite elements were found to be robust in nature to conduct general electromagnetic analyses [57]. 


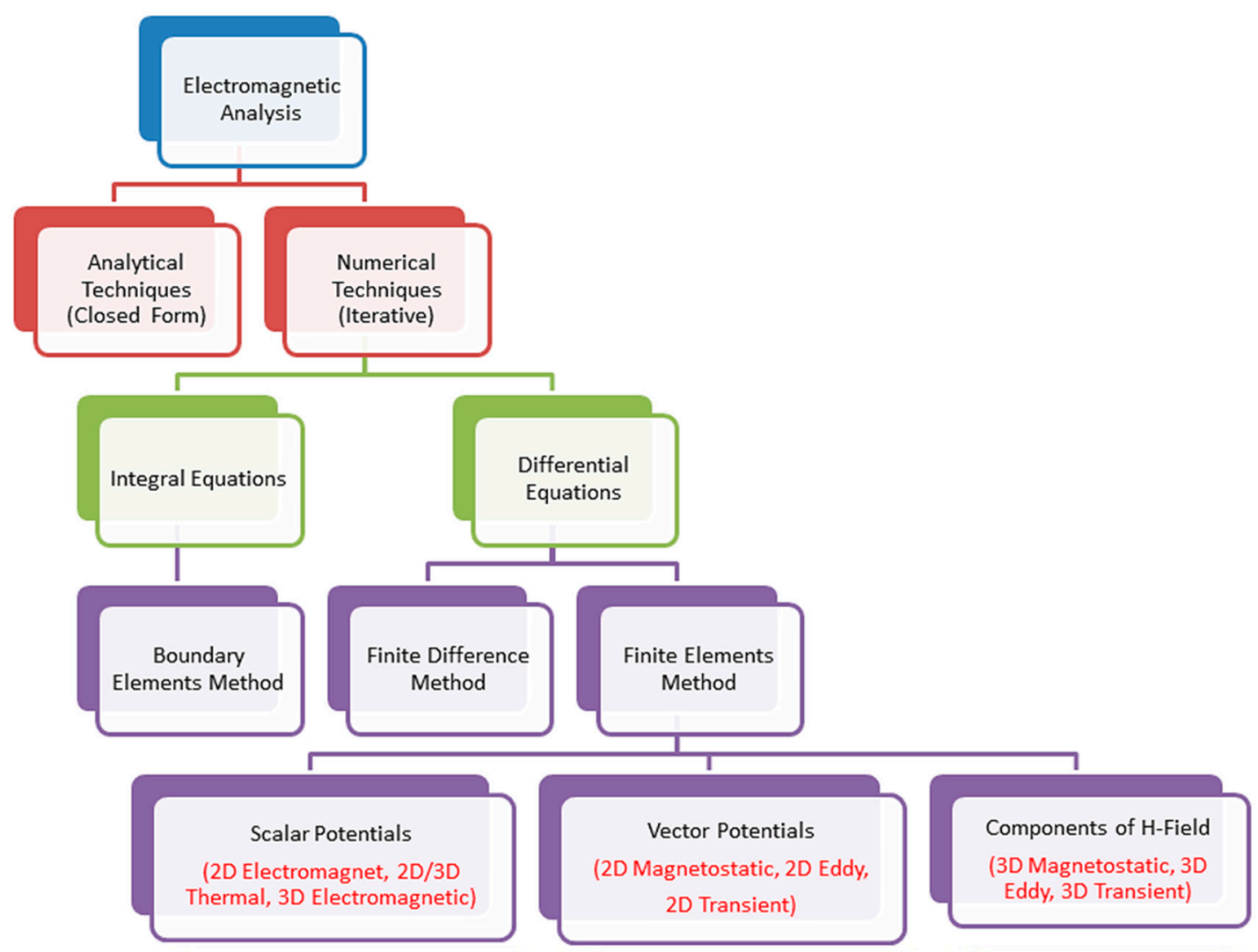

Figure 13. Different methods of electromagnetic analysis [57].

\section{Consideration of Losses Calculation for PMSGs}

One of the important design factors discussed in this study is the determination of losses in PMSGs. In 2010, published a model with an elaborate loss computation and calculation method with updated analytical loss calculation. In this model, conventional losses, for instance, stator core iron losses, ventilation losses, $\mathrm{I}^{2} \mathrm{R}$ losses, and other detailed losses like stator end region losses, were discussed. However, being a separate engine, the cooling caused by the bearing friction and the losses incurred via excitation system were not considered. The components which were lost are discussed here in detail [58].

\section{(a). Iron Losses}

Excluding the stator and rotor windings, there seemed to be losses in eddy current as well as some more losses in entire metallic parts, which can be segregated as follows.

1. Iron losses in (teeth and yoke) stator core which included the impact of rotating fields and harmonics.

2. Eddy current losses on pole shoe surface because of the tooth ripple pulsation and stator winding armature reaction magneto motive force.

3. Eddy current losses in the stator clamping plates.

4. Eddy current losses in the stator clamping fingers.

5. Eddy current losses in the stator core end laminations.

6. Eddy current losses in external metallic air guides.

(b). Winding Losses

Various types of losses in stator, rotor, and damper windings are inclusive in winding losses

1. Stator winding copper $I^{2} R$ losses. 
2. Rotor winding copper $\mathrm{I}^{2} \mathrm{R}$ losses.

3. Due to the tangential slot leakage field, the occurrence of eddy current losses in the stator winding.

4. Due to the radial slot leakage field, the occurrence of eddy current losses in the stator winding.

5. Due to end leakage field, the overhanging of the circulating current and eddy current losses.

6. Damper winding losses due to tooth-ripple pulsation and the stator winding armature reaction magneto-motive force.

7. On the basis of statistical measurements, the rest of the losses were calculated with basic equations.

\section{(c). Ventilation Losses}

Ventilation losses segmented further into following parts

1. Friction losses of rotating parts.

2. Air friction losses of the forced cooling airflow.

3. Pressure generation losses (e.g., fan, inter polar gap, rotor rim) [58].

In 2011, a study [59] of extreme excellence was conducted by on electromagnetic losses which were incurred in direct-driven PMSGs. Using electromagnetic model, the solutions were obtained from FEM. By utilizing a MATLAB-driven model, the researchers performed the simulations. The results obtained inferred that the iron and copper losses were completely based on the rated voltage and rated current. In terms of a fixed output power, the experiment achieved larger machine volume with an increase in rated voltage. Further, higher frequency and increased iron loss were observed in parallel to decrease rated current and reduce copper losses. At the time of simulations, the generator losses were determined for various wind speeds, using which the loss distribution was calculated. Furthermore, they tested an analytical model to predict the eddy current losses in PMSG rotor magnets by feeding a rectifier load. The eddy current loss achieved during time stepping resulted in the coherence of 2-D FEM and coupled-circuit when performing the investigation. In 1997, conducted an experiment and designed losses for the model of a $1 \mathrm{MW}$ machine design prepared in alignment with the parasitic losses. These were stator back-iron reluctance, rotor and stator slotting, rotor reluctance, stator back-iron reluctance, stator module weld loss, rotor eddy-current loss, stator beam loss, the polygon effect, and stator structure cage loss [60]. In 2014, [61] experimented on eddy current losses in PMs of surface-mounted magnet synchronous machines. This study introduced a true analytical method on the basis of magneto-dynamic problem of a conductive ring. The results were obtained and compared with the information retrieved from 3-D FEM analysis. In the analytical model, the effect of the width on magnet loss was considered. The axial effect was considered via a correction coefficient. In the comparison executed, the researchers included impact of the circumferential segmentation, instantaneous losses, effect of the frequency on magnet losses, and induced current density. Through stressing the criticality of the skin effect and magnetic reaction due to magnet currents, this analytical model yielded an accurate measurement of magnet eddy current losses [61].

\section{Faults and Protection}

At the time of designing PMSGs, researchers must be considered for the chance of fault occurrences and protection schemes methods. In 2013, [62] listed the influence of asymmetrical magnet faults upon PMSG rotors. Mechanical looseness, eccentricity, and damage in any one magnet are the most commonly found attributes that result in rotor faults. Further, the rotor eccentricity is caused by unequal distribution of static, dynamic, or mixed air-gap. In the presence of static eccentricity, the air-gap seems to be the least and positioned as per the stator. On the contrary, in the case of dynamic eccentricity, there seems to be no coincidence between the rotor's centers and the center of rotation. Therefore, the minimum air-gap position rotates in line with the rotor. There are notable reasons behind the cause of eccentricities such as looseness, incorrect assembly, load unbalances, misalignment, and sometimes the bending of the rotor. At the time of analysis, the study conducted series as well 
as parallel-connected windings. In order to quantify the demagnetization in a single magnet, the study defined the faulty severity factor. As per the study investigations, one can conclude that, for a generator where all windings are series-connected, the induced EMF value gets decreased due to the demagnetization of a single magnet. Likewise, if the load is a resistive type, the current also may decrease. Therefore, one may not be able to identify the frequency components which are in association with the fault whereas one can observe only the decreased total flux linked to the windings [62]. In 2012, Rodrigues et al expressed his ideas on direct or indirect lightning strokes after thoroughly reviewing the over-voltages and electromagnetic transients [63]. The transient behavior can easily be explained via the lightning protection of the wind turbines accurately, for which the modified version of EMTP (Electro-Magnetic Transient Programme) was utilized. In this study, the researcher adopted a case study model in which two interconnected wind turbines were used so as to study the direct lightning stroke to the blade or the lightning strikes which happens in the soil near a building. Further, this study also conducted a holistic computer simulation in addition to EMTP-RV [63]. Investigation in 2011 [64] which evaluated the fault conditions and identified efficient fault ride-through and protections schemes in electrical systems of both small-scale (land) and large-scale (offshore) wind farms. In their study, the researcher considered two variable-speed generation systems such as PMSGs and DFIGs. After discussing the protection issues associated with DFIGs, the research proposed a new protection scheme as well. Following this proposal, the protection scheme options for fully rated converter and direct-driven PMSGs were analyzed and simulation results were compared.

The development in magnetic materials and its impact on the electric machine design investigated (2007) [65]. In addition to that, few potential faults were also selected using a fault-tolerant system design. Two fault types may occur in the system, of which the electromagnetic faults are as follows:

1. Winding open circuit;

2. Winding short circuit (phase/phase);

3. Winding short circuit at terminals;

4. Turn-to-turn fault in a phase.

The power converter faults are listed herewith

1. Power device open circuit;

2. Power device short circuit;

3. DC link capacitor failure.

One should focus on development of a fault-tolerant system, if the operation needs to be continued even in the presence of faults, if any. In this design, every phase should have a stand-alone single-phase PWM inverter that has a modular system in which the modules are isolated by every phase fault. When a module has less thermal interaction or electrical/magnetic interactions, then the system is likely to proceed with the operations excluding the faulty phase [65].

By 2012, inducted a rotor core design and FEA simulation, to diminish the mechanical stress put upon the core bridge. After considering rotor speed variations, the researcher performed the mechanical transient analysis. The experimental result was presented for the S-N curve (S-N curve is deduced from material test data) of rotor care material so as to assure the validity of the model against fatigue failure [66].

\section{Damping and Oscillation}

In order to handle damping and oscillation, the PMSG-based stability issues in WECS should be taken into consideration. In 2011, a torque compensation strategy was devised [67] based on DC-link current determination of the converters, after the stability challenges faced in PMSG-WECS were studied. In general, the instability issue is caused at the time when generators are in direct connection with the wind turbine during which the speed oscillations occur because of the lack of damper in design, and torsional vibration. With the purpose of reducing the oscillation amplitude and enhancement of the 
system stability, one can make use of generator torque controller. However, due to limited ability, it may impact the WECS' power response. The torque compensation strategy, when deployed with the sole purpose of enabling positive damping of the oscillations, may lead to enhancements in small signal and transient stabilities of the WECS [67]. In 2018, [68] opined the influence on system oscillations because of the grid-connected wind farms. The study focused on the contributions made by the damping of power system oscillations and the assistance rendered by the inner wind turbine oscillations upon the changes in several aspects of power system behavior, which is inclusive of stability. The stability of the power systems gets connected with electro-mechanical interactions and the generator's behavior which is already in connection with the grid. Therefore, the influence of wind power penetration over the power system becomes a key challenge to tackle. In the literature [68], an elaborate investigation was conducted about the oscillations in power systems and its influence and control schemes in the wind farms for various wind turbine technologies [68]. The growing technologies that focus on magnetic gears were the primary theme of the study conducted [69] (2011). The concept of magnetic gears has an advantage of dealing with inherent overload capability surpassing the mechanical gears. However, there is a less amount of torsional stiffness found in magnetic gears than their counterparts i.e., mechanical gears. This leads to oscillations at the time of transient changes in load and speed alike, and the damper windings utilized in synchronous generators to alleviate the oscillations that occur due to transients [69]. In a study conducted in 1996, the researchers display the damping of PMSG power-angle oscillations in terms of wind turbine applications [70]. The small pole pitch present in the generator allows it to work in every low speed and this is conjoined with the wind turbine, thus a direct electrical grid connection is maintained. In this research paper, an alternative damping system was proposed in which the stator is allowed to confine the rotational movement through a connection with the wind turbine that is located near a spring and mechanical damper. This proposed method enables high damping of power-angle oscillations when compared to conventional damper windings. The design's efficiency can be illustrated via the generator's response to initiate the changes in driving torque. In order to showcase the new design's vibrant nature and viability, the generator's behavior on synchronization as well as on operation front, where there is a difference in wind occurs, is described [70].

\section{Short Circuit}

In 2011, [68] stressed the occurrence of sudden short circuit when applied in large PMG machines thus denoting the differences in short-circuit behavior amongst the would-field generator and the PMG. With the help of FEM analytics, the researcher calculated the sub-transient reactance and time constants of the PMG and utilized it at the typical circuit theory simulation in short-circuit fault. The FEM was then used in the risk evaluation of magnetization loss in magnets. Being complex, the transient magnetic field looks for transient non-linear circuit-coupled FEA in 3-D in association with voltage-source excitation. Various calculation methods where summarized in this research paper with further discussions on implications of futuristic design and PMG application after considering the attributes that are relevant to application of standard tests and specifications [71].

\section{Several Aspects of Cost Factor}

In the study conducted by Salem Alshibani et al. (2014) [72], the high CAPEX (Capital Expenditure) issue was taken into account since, at the beginning of a project, it is always a hindrance for such techniques, especially in case of PMSGs. The study proposed a method, which utilized to assess typical PMSGs designed and reported in this article. The results of the proposed method were compared with the results of the traditional methods. The results inferred that the lifetime cycle assessment (LCA) seemed to favor the gearless PMSGs that incur high CAPEX. Further, in the case of inclusion of lifetime cost in the design optimization, the scenario develops machines which can yield significantly higher lifetime revenues than the extra CAPEX required [72]. Figures 14 and 15 compare the CAPEX values of geared as well as gearless PMSGs in a range of power ratings with percentage. 


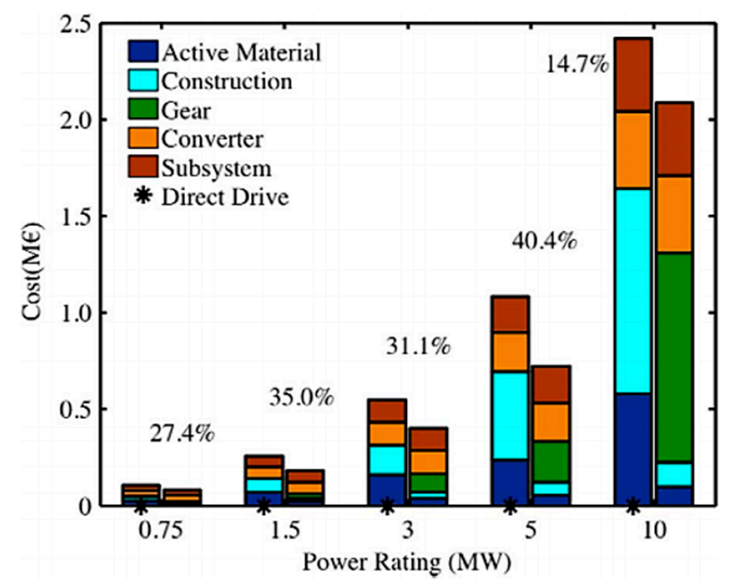

Figure 14. Depicted CAPEX (Capital Expenditure) comparison of geared and gearless PMSGs at a range of power ratings with percentage difference in cost shown at each power level [72].

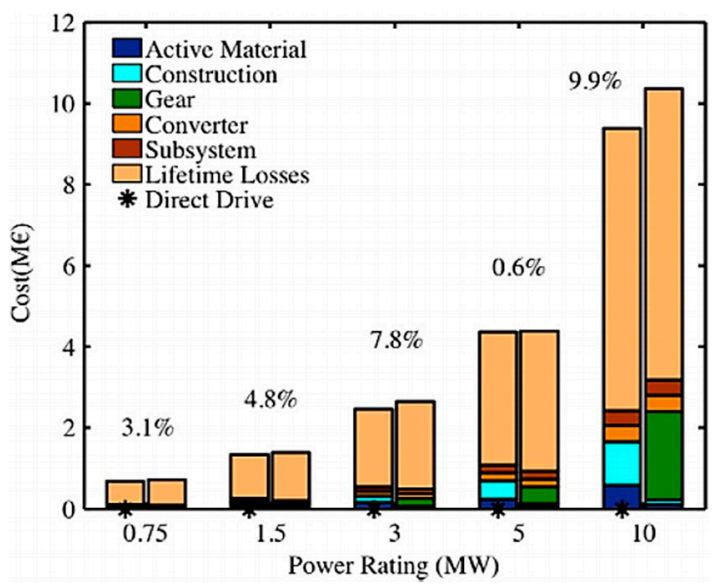

Figure 15. Cost comparisons of the machines with lifetime losses cost added and gear cost calculated twice. The percentage difference in cost is shown at each power level [72].

To conclude, it can be inferred that higher power rating-based wind turbines are the most preferred ones in reducing the development and maintenance time and eventually increasing the energy yield [72].

\section{Soft Computing Technique Based Optimization Used for PMSGs}

There are two critical issues that influence an electrical machine's optimal design considering the usage of FEM, the computation time from FEM simulation, and the different parameters concerned with the electrical machine. In the present day scenario, the use of soft computing techniques-based optimization has gained momentum owing to the use of the statistical analysis with multiple correlation coefficients and moving least squares (MLS) approximation as proposed (2007) which are compatible with the electrical machines [73]. In general parlance, the process of optimization includes several computations which are all dependent on parameters; the effort of computation is very minimal when compared to the time that is saved. Such a method is assessed by the same application to synchronous machine's optimal design. The results of such analysis reveal the increase in the torque per weight ratio by $13 \%$ when compared with the results that are acquired from traditional optimization techniques [73]. In 2010, [74] used the Fuzzy and FEM method for the analysis of the comparison that includes leakage field analysis witnessed in the electrical generator. The process of leakage field analysis is performed by developing a fuzzy model of the generator with the technology called adaptive neuro-fuzzy inference system (ANFIS). In this regard, the researcher performed a comparative evaluation on fuzzy model and FEM model wherein a good correlation was found to be present 
between them [74]. Furthermore, a study (2008) [75] revealed the new and novel approaches towards automating optimization processes that are manual, and examined the implementation obstacles that are witnessed by the engineering community. Based on the effort for design evaluation and the degrees of freedom viewpoints, engineering design optimization was subjected to classification. In the previous research, the researchers presented a holistic view on the various design optimization approaches. Furthermore, the major challenge witnessed was scalability for the techniques of design optimization considered in the study. Large-scale optimization requires effective algorithms such as swarm intelligence and a considerable computing power [75]. However, 2001, [76] proposed the use of a neural network in comparison with the Finite Element Technique (FET) based sensitivity analysis for the optimization of permanent magnet generators. In 2012, [77] further identified the challenges that were witnessed during design optimization for minimizing or maximizing the fitness function which positively influence the design purpose. Genetic algorithm which is incorporated in the optimization technique that is population based does not consider certain inferences, such as the magnet, copper, and magnetic laminations, and raw active materials. The main intention towards the reduction of the fitness function is based on the cost of energy that is generated by the system which further accounts for the variables that are uncertain in nature [77]. In 2009, [25] further explored the use of direct-drive PM wind generation system optimum design models wherein the PM was designed and developed using enhanced genetic algorithm with a PM generator fitted with $500 \mathrm{~kW}$ direct drive wherein the minimization of the active material cost tends to improve the design optimization effectiveness.

In 2009 used the concept of direct-drive PM wind generation system optimum design models in which the PM is developed using an improvised genetic algorithm along with a $500 \mathrm{~kW}$ direct drive PM generator; this actually reduces the cost of generator active material which further illustrates design optimization effectiveness [25]. Furthermore, [78] (2007) proposed a novel approach for the design of electrical rotating machines wherein a rational solution of predesign was done by integrating exact global optimization algorithms and analytical model. However, prior to developing an extensive prototype, validation of previous solutions should be performed using FEM. The purpose of the previous research was to extend the accurate global optimization algorithm through the introduction of an automatic numeric tool. Such a novel technique is used in resolving rationally the design problems. Furthermore, several examples were evaluated to examine the effectiveness of the novel technique [78]. In 2008, [79] further established a new hybrid machine with 36/24 pole outer rotor permanent magnet (PM) that is directly coupled with a wind power generator. For effective control of the flux control, two excitation (PMs and DC field windings) hybridization in the double-layer stator is utilized. This result in constant output with wide range of speeds and a load varying where examined. In 2001, [80] further used genetic algorithms wherein a new algorithm called orthogonal genetic algorithm along with quantization/quantification for global numerical optimization was used with continuous variables. Furthermore, a quantization technique and orthogonal design were used for the development of a new crossover operator; this crossover operator generates representative sample points which are small, however are a potential offspring. Such a proposed algorithm solves 15 benchmark problems with 30-100 dimensions belonging to the local minima [80]. It was 2005 arrived at new dimensions in this research area of evolutionary computation and structural design [81]. Furthermore, [82] (2008) examined soft computing (SC) techniques associated with the design of engineering concepts. Through the inspection of soft computing methods, techniques, and their competence, to further address the high complexity issues and design tasks, the researcher reviewed Fuzzy logic (FL), artificial neural networks (ANN), and Genetic Algorithms (GA) [82]. In 2012, [83] further made an overview to compare research that was conducted to optimize the parametrization of machining process of modern and conventional machining. Following are the most important techniques used: genetic algorithm (GA), particle swarm optimization (PSO), simulated annealing (SA), artificial bee colony (ABC) algorithm, and ant colony optimization (ACO). Amongst the aforementioned algorithms, GA is widely applied in the literature [83]. In 2004, [84] proposed a new solution called the multi-agent genetic algorithm (MAGA) which is an integration of the genetic algorithms and multi-agent systems to solve the problem 
of global numerical optimization. In 2008, [85] further proposed a disagreement versus randomness in the various SC techniques. In 2011, [86] further reviewed the state-of-the-art research developments associated with the use of soft computing techniques used for the optimization of problems associated with design, planning, and control in the field of sustainable and renewable energy. Furthermore, several soft computing methods were reviewed and presented regarding the current state of the art in computational optimization methods applied to renewable and sustainable energy, wherein a vibrant visualization of the state-of-the-art research progresses was proposed [86]. It is important to generate random numbers using soft computing methods, as random numbers are used during the beginning of the estimation or during the processes of learning and searching. When compared between simultaneous randomness consideration and opposition and pure randomness, it was revealed that the former is better than the recent results acquired from evolutionary algorithms, neural networks, and reinforcement learning. To further increase the performance of soft computing algorithms, it was revealed that opposition-based learning provides an inclining effect. This was experimentally and mathematically proven that SC has better merits when applied to improve the differential evolution (DE) [86]. In 2010, [87] also presented the Genetic algorithm (GA) with memetic algorithm and MADS (Mesh Adaptive Direct Search) for the optimal design of an electric machine. To acquire an effective optimal design of an electric machine with longer computation time and many local optima, the previous research proposed a hybrid algorithm to acquire global optimum. To maximize further Annual Energy Production (AEP), the prospective algorithm was referred. By 2006, [88] classified the modelling and optimization techniques for process problems shows in Figure 16, which displays the conventional and non-conventional optimization techniques and tools used in this regard.

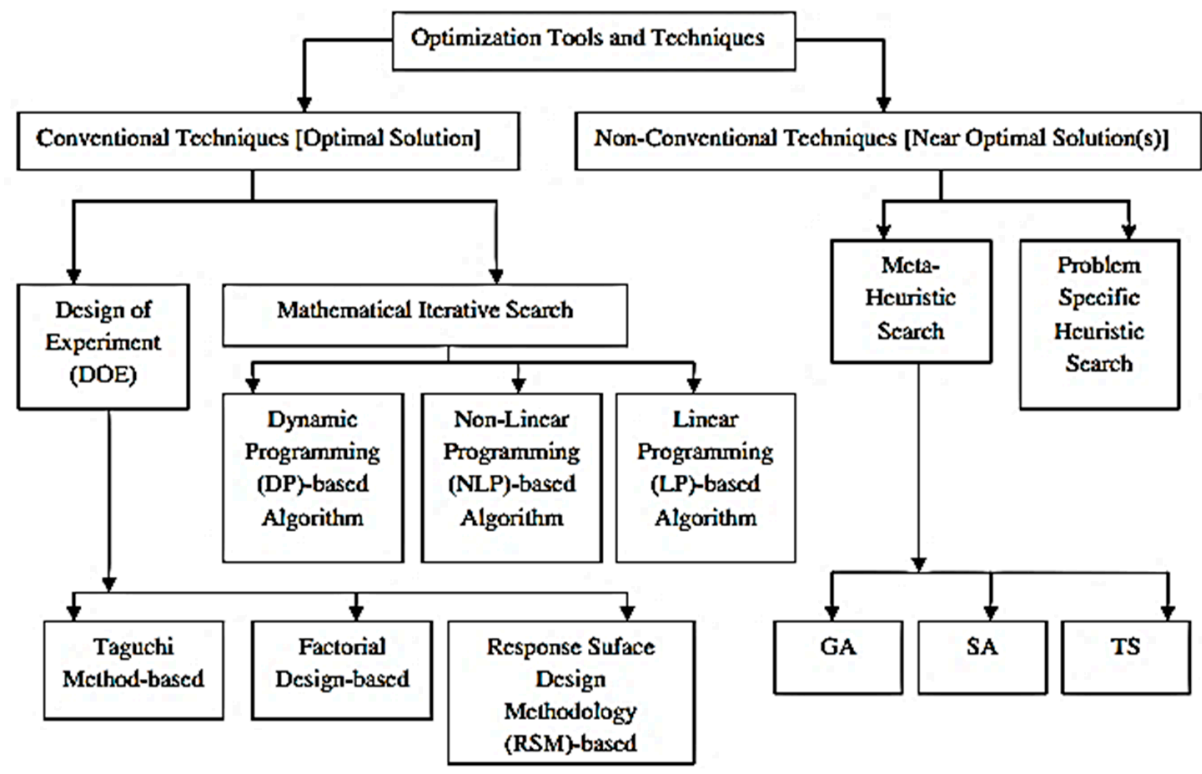

Figure 16. Conventional and non-conventional optimization tools and techniques [88].

To further conclude, it was deemed that MADS is combined with GA as an effective computation time reduction method for optimal PM wind generator design and is considered over other parallel computing methods [89]. Further offered a type of multidisciplinary design and optimization (MDO) of a diffuser for an incompressible and steady magneto-hydrodynamic (MHD) method. The design problem can be resolved using GA-based programme that is optimized with the FEM based MHD simulation technique for which least-square FEM was used and developed in later research [89]. In 2017, [90] presented about Multiple Criteria Decision Making (MCDM) concepts and has been used for economics analysis. Similarly, this concept can be used for lifecycle cost analysis of machine design [90]. In (2002) [91] presented the non-dominated sorting GA to mitigate the performance related problems wherein the performance was analyzed through the comparison of the results from the 
other four algorithms. Further discussion was performed on the multi-objective optimization process solution using evolutionary algorithms, wherein the findings of the research revealed effectiveness against analytical and electro-magnetic problems [91]. Furthermore, [92] (2001) displayed an approach that was used to design PM for wind power applications wherein the approach was made up of two phases: preliminary design stage and optimization stage. In 2008, [93] further examined the use of Differential Evolution (DE) and Particle Swarm Optimization (POS) Algorithms with technical analysis. It was ascertained that the Artificial Bee Colony (ABC) algorithm could be used as an innovative swarm optimization algorithm with fine results of numerical optimization.

Furthermore, [94] (2011) proposed an enhanced algorithm called the fast mutation artificial bee colony algorithm (FMABC). In 2012 proposed an improved ABC algorithm, which was used to solve numerical optimization issues, which further improved the capability of the ABC algorithm's exploitation feature. An alternate search mechanism and a varying probability function were proposed by the previous researcher. Seven numerical optimization problems were tested on the enhanced $A B C$ algorithm [95].

In 2012, further utilized genetic algorithm (GA) for the achievement of an optimal design for an axial-flux PMSG (AFPMSG) [96]. In 2009, [97] proposed an approach based on a numerical optimization algorithm wherein a generalized receding horizon control of fuzzy systems was proposed. To further resolve generic fuzzy dynamic systems' optimal control problem, a numerical method was developed. Fine optimization was developed in the previous research.

The researcher made a thoughtful understanding of soft computation techniques in the electrical engineering field applications, with integrated pseudo-code operational summaries [98]. In 2010, [99] considered population-based algorithm and its application to solve numerical optimization problems. In certain cases, there are complexities in computing search problems which is associated with high dimensionality of search spaces. Until there is an employment of appropriate approaches, a search process could reduce effectiveness and increase cost. The use of nature inspired algorithms could tackle such difficulties. For example, fish schools tend to increase the mutual survivability since a large number of constituent individuals are deployed.

In 2008, first to introduce a method that searches high dimensional spaces that consider account behaviors that are obtained from fish schools. The derived algorithm-Fish-School Search (FSS) was made up of three operators: feeding, breeding, and swimming. In a cumulative scale, these operators tend to afford the evoked computation: (i) wide-ranging search abilities, (ii) automatic capability to switch between exploitation and exploration, and (iii) self-adaptable search process for global guidance [100].

S.L. Ho et al. (2006) examined the use of particle swarm optimization (PSO) methods wherein the previous research considered several variables such as age; new strategies were figured out to examine the optimum particle solutions, the original formula for velocity updating, and intensified search phase integration with enhanced PSO method. The findings of the previous research revealed that the proposed method contains a refined ability to perform a pinpointing search and the overall global ability improved when compared to traditional PSOs [101].

It was [102] offered the use of support vector machine (SVM) classifier for the detection of broken electrical induction machines. Furthermore, the previous researchers also considered the analysis of Gaussian, linear and quadratic kernel function as opposed to the error rate and the support vector numbers. The findings of the previous researchers revealed the successful detection of broken bars in different situations wherein there also evidences fast, precise, and robust load changes which tend to qualify for the right use of such techniques in real-time online applications in industrial drives.

Furthermore, in 2002 proposed a tabu-search algorithm to identify multi objective optimal design problems' pareto solutions from which there is a utilization of the contact algorithm to assess the previous aspects. During the initiation of the iteration cycle, identification of the new current points, fitness sharing function, and ranking selection approaches are introduced. A more detailed explanation of the numerical results is displayed in the previous research to highlight the power of the proposed 
algorithm to ensure that there is uniform sampling performed which yields Pareto optimal front of the multi-objective design problems. Furthermore, effective execution strategies for the proposed algorithms were also displayed [103].

In 2011, further displayed the Improved Discrete Particle Swarm Optimization (IDPSO) searching technique, which is applied on the head of an electromagnet and for the optimization of the magnetic field gradient. For the previous research, COMSOL software was used for the measurement of the magnetic forces and field. The aim of the optimization algorithm is the search of optimal pole shape geometry in a refined manner, which results in the distribution of the homogeneous magnetic field with the desired holding force in the specific area of interest [104].

Furthermore, [105] (2007) displayed an innovative recursive fuzzy logic categorizing (R-FL-C) strategy for the PM generators design approach that is utilized to mitigate search space and for expelling the local minima in due course of the process of optimization. In the previous research, finite element state space models are used to examine the space database with the knowledge that is acquired from off-line.

In 2012, [106] assessed the numerical functional optimization wherein the use of artificial bee colony optimization led the researcher to derive the use of the same bee swarm foraging behavior in their approaches. Furthermore, the ABS's efficacy was found to be high when compared with the genetic algorithm (GA), ant colony optimization (ACO), and the Particle swarm optimization (PSO). Though the ABC technique is found to be pretty important and efficient during exploration, the capacities associated with exploitation are found to be poor with issues regarding convergence speed in several instances. To mitigate this, the researcher further introduced the improved $A B C$ algorithm or the I-ABC, which during the process of search with refining used the acceleration and inertia weight as the fitness functions.

In addition, [107] (2012) provided a heuristic structural optimization for the Surface Mounted PMSG. The use of structural optimization is the process of identifying the material distribution in an optimal way in every machine part; this technique is very prevalent in the field of mechanical engineering. Similarly, the use of structural optimization can also be witnessed in the field of electrical engineering. When compared to the other methods reported to deploy the continuous models for the elaboration of the material properties with Heuristic Search Algorithm [107], it gives a solution to the structural optimization issues.

By 2019, [108] proposed an identification method on K-means-singular value decomposition and least squares support vector machine which the simulations were proposed for voltage sags based upon an annealing algorithm for multi-objective optimization. To gain the pareto solutions in a significant manner. This is completely dependent on Pareto and can successfully be introduced in addition to parameter and objective space strings. The novel method proposed in this study questions the stop criterion, new rank formula, fitness sharing functions, and other such enhancements. For the purpose of validating, the proposed method's robustness, the study validated two numerical examples [108].

In 2001, [109] proposed an enhanced tabu-search algorithm to practically applied, it when finding optimal designs for electromagnetic devices. In parallel, the study also conducted team workshops and mathematical test functions. Based on the numerical results, it was inferred that there is a less significant iteration number achieved for the proposed method when compared with simulated annealing and other such algorithms.

In 2008, proposed a novel methodology with reference to PSO in order to find out the parametrically non-linear model structure. In this study, an existing method used in PMSM's dq-model to identify the parameters. Both the disturbed load torque as well as the motor stator resistance was established for PMSM variable-frequency drive system application. In order to question the efficiency of the identification method, the study conducted a simulation and the experimental results were provided. The results inferred excellent precision in terms of time-varying parameters when the PSO algorithm was used [110]. 
In the study conducted 2000), an auto-learning simulated annealing algorithm was proposed. This algorithm was developed by collaborating simulation annealing as well as the characteristics of the domain elimination method. This study utilized the standard mathematical function to assess the algorithm in addition to optimization of the power transformer practical end region [111].

In 2005, [112] demonstrated single as well as multi-objective optimizations by experimenting with a PMSM with rotor feedback with the help of a Genetic Algorithm. This artefact's extensions are nothing but the implementation of core losses cited with the help of the Steinmetz approach. A few other up-front changes are the modifications in tooth shape (especially the base), addition of voltage drawbacks, and changes in the volume expression for addition of end turns.

In the study conducted by [113] (2005), an improved Ant Colony Optimization Algorithm was proposed to be used in Electro-Magnetic Device Designs. The experiment deployed the algorithm in an inverse problem along with a mathematical function where its performance was contrasted with other better-designed methods.

A comparative study was conducted (2007) between the performance of ABCs upon the optimization of numerical function with swarm intelligence and population-based algorithms such as PSO, GA, and Particle-Swarm Inspired Evolutionary Algorithm (PS-EA) [114]. In order to explore the performance of the $\mathrm{ABC}$, a total of five high dimensional benchmark functions that consisted of multi-modality were deployed. From the simulation results, the authors made a strong recommendation that the proposed algorithm is capable of expelling local minimum and can be used well in multi-variable multi-modal function optimization. The scope for future researchers in this study was the investigation of influence exerted by the control parameters in the convergence speed and performance of $A B C$ [114].

In 2009, a comparative study conducted to assess the performance of $A B C$ algorithm with Evolution Strategy (ES), DE, GA, and PSO using a large set of unconstrained test functions. From the results, it was concluded that there was an excellent performance exhibited by the $A B C$ algorithm when compared to other algorithms, though the study made use of only less-control parameters thereby efficiently solving multi-dimensional as well as multi-model optimization problems [115]. The results further inferred that the performance of the $\mathrm{ABC}$ algorithm is superior compared to other such algorithms.

A beneficial design procedure was proposed (2012) for the controller utilized in the frequency converter of a variable speed wind turbine (VSWT)-driven PMSG with GA and RSM [116]. A mess-less technique was recommend by the study conducted in 2004, which focused on connecting the radial basis functions (RBFs) as well as wavelets. This new method proposed in this study leveraged the advantages of RBFs as well as the wavelets. In order to maintain the linear independence as well as consistency, the bridging scales were utilized so as to safeguard the mathematical properties. With the purpose of validating the proposed method, a numerical example was utilized [117].

A hybrid Genetic Algorithm (GA) was proposed in 2003 [118], in order to optimize the electromagnetic topology. After taking a 2-D encoding technique into account, the geometrical topology was at first applied to electromagnetic topology. In the later stages for the crossover operator, the study utilized a 2-D geographic crossover. In order to enhance the convergence features, the study used a novel local optimization algorithm, otherwise called an on/off sensitivity method, which is hybridized with 2-D encoded GA. Once the algorithm was verified with different case studies, the results were published [118].

\section{Novel Topology Development in PMSGs}

In 2012 stated the assessment of low maintenance slip-synchronous, PM wind generator, which was developed using the concept of PM induction generator [119]. In 1926 introduced the PMIG (Permanent Magnet Induction Generator) concept upon which the slip-synchronous permanent magnet generator (SS-PMG) was constructed. In generator design, there exists an induction machine cage-rotor, traditional stator winding along with an add-on of second free-rotating PM-rotor. The second PM-rotor runs synchronous speed while the cage-rotor operates at a relative slip speed in accordance to the PM 
rotor and rotating synchronous stator field. This is a gearless wind turbine generator that is connected with the grid directly i.e., no power electronic convertor or such behavior is required in the drive train. In the summary developed by [17] (2014), a comparison was performed between large-sized wind turbines which can produce more electricity at less cost with small-sized turbines. This comparison was executed since the costs involved in experimental set-up and maintenance do not impact the size of the machine. Therefore, more than $7 \mathrm{MW}$ output power is being achieved from today's wind generators. For instance, from 2011, Enercon manufacturing an E-126/7500 wind turbine with 7.5 MW power capacity. At present, Sway Turbine and Windtec Solutions are in the process of developing $10 \mathrm{MW}$ wind turbine generators which might hit the commercial markets in 2015 [17]. Figure 17 shows the voltage ratings of seven various models of common wind turbine generators with respect to the turbine power which clearly depicts the model performance.

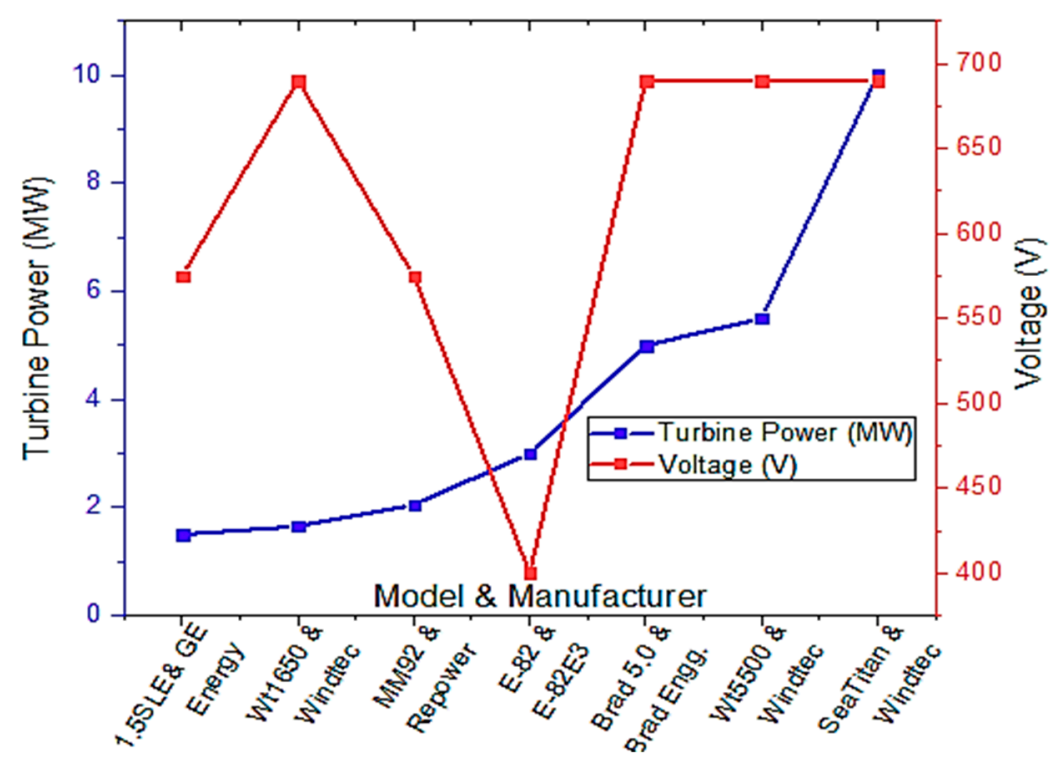

Figure 17. Summary of the voltage ratings of a few common wind turbine generators [15].

An innovative model with a Surface-Inserted Permanent Magnets Synchronous Generator was proposed in 2011, with air slots in the rotor that can be adjusted. This model removes the disadvantage present in PMSGs i.e. fluctuation of regulating voltage. When a comparison was performed between conventional machines and superconducting machines, it was found that the latter exhibited novel advantages such as efficiency, compactness, lightweight and significant stable operation in power systems [120].

In 2007 proposed an eccentricity topology with a promise to enhance the power density and made use of it in the design, development, and testing on an eight-pole superconducting rotating machine. Further, the study discussed the results retrieved from the magnetic scalar potential from a Coulomb formulation by Markov Chain Monte Carlo (MCMC) method. Additionally, the flux density was calculated using derivation from the regularization method. With the purpose of reducing the computation time, the MCMC method was deployed which in turn perform the magnetic scalar calculations in specific regions of discrete geometry. By using $\mathrm{YBaCuO}$ high-temperature superconducting (HTS) bulk plates and low temperature superconducting NbTi wires, a high magnetic field was generated. In order to increase the cooling operation, there is a stationary superconducting inductor and a rotating armature coiled with copper wires present in the superconducting machine [121].

A detailed differentiation study was conducted [122] (2012) on the differences in development and settlement of active materials for transversal-flux machines from radial and axial ones. Lower stator copper losses were gained by increased windings space in the absence of any impact from 
the available space for flux in the transversal flux. As the electromagnetic structure is sophisticated, the transversal-flux machines seemed to be costly [122].

A novel low-fare methodology was proposed in 2012 to develop wind turbine electric generators from the generator from the burnt-out squirrel cage induction motors. The author first detailed the list of properties generally required for a wind turbine generator following which the methodology described the PMG, workability, multi-pole, and low-speed. The study conducted a cost comparative analysis and performance comparative analysis based on the test results achieved from a $500 \mathrm{~W}$ generator run at $900 \mathrm{RPM}$ and a $1500 \mathrm{~W}$ generator at $650 \mathrm{RPM}$ [123].

The efficiency of an air-cored PMSG was estimated in the study conducted [124] (2011) using finite elements and equivalent circuit modelling. The emerging trends showcase that the air-cored machines are predominantly used in wind energy systems. Instead of iron, the magnets which are captivated between the mild-steel-based rotors are present. At zero-load, the two-sided, axial-flux, air-cored machine's flux path can be seen as a stable magnetic flux that crosses axially from a magnet on one rotor to the opposite rotor which is a facing magnet. Further, the study stated that the coil is held by the stator on a plane in the middle of two magnetic sets [124].

In 2012 [125], an alternative viable solution was proposed the traditional PMSGs at MW level in direct-drive wind turbine applications via a Halbach array. It is a must to optimize the machine dimensions in order to achieve the maximum benefit of the Halbach array. This research article provides an overview of calculating the Halbach array application using analytical equations which are prevalent in the studies published earlier. The study recorded extraordinary performance by making few modifications in the existing PMSG design in which a constant magnet volume is maintained. When compared, the conventional array seemed to be more valued than the Halbach array at the time of considering the critical rotor radius. When the number of poles were increased, the critical radius got shifted to larger sizes and thus it allowed a positive leverage of the Halbach array at MW level. The analytical equation findings were verified using FEA simulation [125].

In 2008 [126], Halbach magnet array with the help of the numerical optimization method, which in turn relied upon finite element analysis. The magnetization direction of every element was designated as the design variable. In order to enhance the repulsive, attractive, and tangential magnetic forces present between the magnetic layers, the researcher investigated the optimal magnet arrays composed of two and three linear magnet layers. Two and three magnet rings altogether are present in a torsional spring and it receives the tangential force maximized by the magnet array. In this study, the researcher employed few optimization techniques such as adjoint variable methods and sequential linear programming in 2-D finite element analysis [126].

In 2005 developed a theoretical study about the magnetic circuit for a longitudinal flux PM synchronous linear generator. In order to assess the machine performance, the researcher used a coupled field and circuit model which was solved using the time-stepping finite-element technique [127]. In 2008 [128], and 2010 [129], conducted a comparison of different configurations in an axial-flux nine-phase concentrated-winding PMSG for a direct-drive wind turbine.

Various prototypes where investigated by [130] (2012) in which one of the prototypes demonstrated that the active mass of a PMG unit in a SS-PMG curtailed in a considerable fashion. For different slip-PMG concepts, the evaluation was also performed. To be specific, it is feasible to have a notable amount of minimization in active and PM mass for the new brushless-DC winding slip-PMG in comparison to existing non-overlap winding configurations. Further, it can be projected that the copper can be replaced by aluminum and there is no need to increase the mass of slip-PMG without changing the machine cost performance [130].

A low-speed three-phase generator was considered in 2014 with high induced voltage, low harmonic distortion as well as high generator efficiency, optimal generator parameters such as pole-arc to pole-pitch ratio and stator-slot-shoes dimension topology for investigation. For the purpose of obtaining sinusoidal induced voltages in stator windings, the researcher arranged the PMs in rotor structure and adopted the magnetization direction in an appropriate manner [131]. An insight was 
published (2006) about the basis behind the development of PMSG, a novel hybrid in Hybrid Excitation Permanent Magnet Synchronous Generator (HEPMSG). It was developed through the insertion of an exciting winding in rotor or stator [132].

In 2008, [133] developed the Flux Reversal Machine (FRM) coupled with a doubly salient stator permanent magnet machine in addition to flux linkage reversal present in the stator concentrated winding. The study conducted a comparative analysis on Full Pitch Winding Flux Reversal Machine (FPFRM) and Conventional Concentrated Stator Pole Winding FRM (CSPFRM) on the design. The results revealed that FPFRM exhibited high power density than CSPFRM [133].

In order to shuffle the standard claw pole alternator in the place of automobile application, a single-phase FRM was introduced. It has few advantages, such as it has a simple construction process, expresses high-power density, low in inertia etc. Reference [134] (2010) investigated and proposed a distributed winding for FRM (Flux Removal Machine). A high-power density is provided by FPFRM and it enhances the efficiency as well. Being a doubly-salient Permanent Magnet machine with concentrated windings, FRM has advantages of both Switched Reluctance Machine and Permanent Magnet (PM) machines. FEM analysis was carried out in order to achieve the induced EMF, winding inductances, and flux linkages. The winding function strategy received the inductance of both the machines and it was compared with FEM results. On the basis of fabricated 'electrical gear', the power densities of both CSPFRM and FPFRM with PMSM were compared. The gear ratios were provided from various FRM configurations. As the design of CSPFRM, FPFRM, and PMSM are similar with respect to outer dimensions, the volume of the magnet, and the rotor speed, the comparison of those three machines were graphically represented in Figure 18. From the graphical representation, it is observed that the machine FPFRM requires very high compensating $\mathrm{kVAr}$, when compared to CSPFRM and PMSM. However, as far as active weight $/ \mathrm{kVA}$ is concerned the FPFRM is less when compared with other two [134].

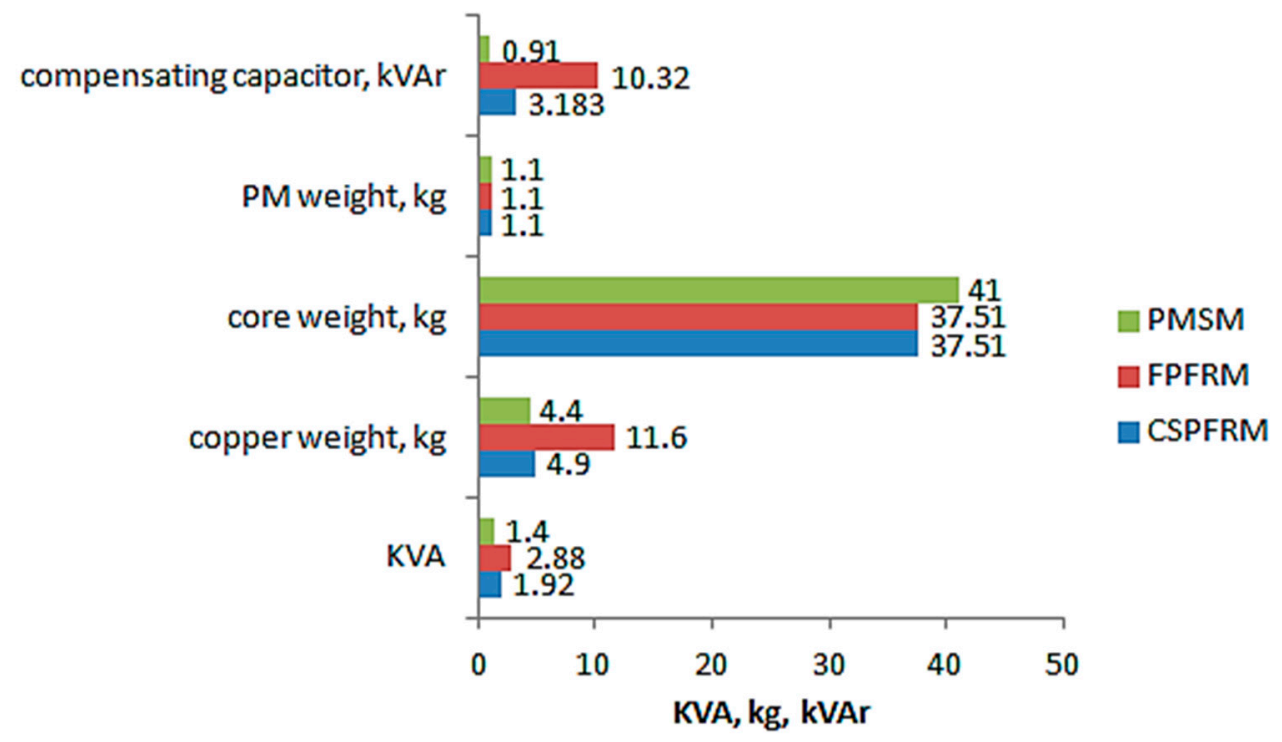

Figure 18. Comparison of Conventional Concentrated Stator Pole Winding Flux Reversal Machine (CSPFRM), Full Pitch Winding Flux Reversal Machine (FPFRM), and PMSM [134].

In 2007, [135] developed low-revolution magneto-electric generators which are custom designed for wind power engineering applications. The best and efficient way to diminish the own drag torque is to incorporate a magnetic rake so that the EMF do not exhibit a significant decrease and the adaptability of the magneto electric machine design is preserved as per the manufacturing. Among the available ones, the best alternative is the one, which is found in the magnetic rakes situated outside and inside of the rotor inductors, which is equivalent to the width of the spline way slots that were found inside and outside of the stator. 
An optimal design method was proposed in 2009 [136], in which a double-layer permanent magnet (PM) Dual Mechanical Port (DMP) machine was present for wind power application with random low-wind turbine speed input and stable steep synchronous speed output. The torque was compared between the outer-rotor and inner-rotor. Further, they also compared the THD variations with a pole arc co-efficient for inner-rotor and stator winding [136].

With the purpose of overcoming the potential barriers of dimension, cost, and reliability, in 2011 [137], a multi-generator architecture was recommended. They suggested that a total of two PMSGs should be shared with one turbine-driven shaft. The outputs need to be recorded from the two PMSGs, and then rectified in order to be connected in series with an intermediate DC chopper, whereas the back-end inverter is provided with similar option [137].

In 2012, [138] developed an investigation about the novel form of transvers and axial-flux magnetic fields of the PMSG. With novel machine configuration such as rotation, the flow of the main flux would be in the transverse direction. A novel Outer Rotor-Permanent Magnet (PM) Vernier (OR-PMV) machine was introduced [139] (2010) for direct-driven wind power generation that comes packed with low speed. This is because the wind power can be easily capture, and it triggers the high-speed rotating field design in order to enhance the power density [139].

In 2003, [140] developed an operating principle called Consequent-Pole Permanent-Magnet Machine. In addition to the finite element analysis and sizing analysis, the experimental results were achieved for the prototype machine. There are many advantages associated with CPPM machine, one of which is the control on air-gap flux level excluding the demagnetization risk from magnetic pieces. In terms of low-reluctance iron poles, it is possible to execute the control action. In addition to the low field AT requirement, a wide range of air-gap flux control was also yield and this could be leveraged to either increase or diminish the air-gap flux.

In 2012, [141] sought the winding functional theory as the basis and detailed the inductance of a multi-phase synchronous machine supported with a PM or a wound field rotor. Due to the three magneto-static simulation results produced from simple machine-based geometric models, it is easy to determine the permeance function. For the inductance of stator phase, inductance of phase-to-field, and PM flux linkage calculations, the existing method was used. In order to have an accurate incorporation in numerical machine models that pertain to dynamic simulations, the study proposed the machine inductances, which are relevant to Fourier-series expansion.

A novel interpolating strategy was proposed in 2011 [142] for air-gaps by antiperiodic boundary condition when applied to AFPMSG. With the help of coupled-circuit, element analysis, and time-stepping, the performance of AFPMSG in case of isolated load was investigated. The investigation was also conducted upon the performance of short circuit. In order to produce the results of the accurate analysis, the researcher used second-order serendipity quadrilateral elements [142].

A novel three-phase 12/8-pole doubly salient permanent magnet (DSPM) machine was investigated in 2006 [143] so that it can be used in wind power generation. This in turn can be utilized to design and study the recommended DSPM generator i.e., a novel machine structure design which yields high efficiency, high power density, and high robustness in the device of system operation. In order to obtain static characteristics of the proposed generated, the researcher used FEM [143].

In 2017, [144] executed a complete model, design, and development of a novel slip-synchronous Permanent Magnet (PM) wind generator for direct-drive direct-grid connection. There is variation present in the proposed generator with that of the traditional PM induction generators mentioned in the literature. The non-overlap winding was used in the proposed model for the very first time. For the generator design to be effective, a mixture of analytical, finite element calculation and optimized design methods were employed by the researcher. The researcher minimized the critical design parameters such as load torque ripple and no-load cogging torque to the best possible minimum level in the design optimization stage. The model was verified, and the design was completed with measurements of wind generator system prototype. 
Under linear condition (2007) [145] compared the predictions of the two methods listed herewith in the calculation of electro-magnetic torque with inductance of a synchronous reluctance machine.

1. Winding function analysis (WFA);

2. Finite-element analysis (FEA).

In the methods mentioned in the literature, the stator winding connections, stator slot effects, as well as the rotor geometry, were considered. The WFA simulation results were contrasted with that of the 2-D FEA whereas the results were the same. In case of magnetic linear condition, the winding function method seems to be quick, incur less computational costs, and quite simple.

In 2009, [146] analyzed the Hybrid Exciting Synchronous Generator (HESG) in addition to unique operating principles and structure. The upkeep required for the main output is generally taken out by PM generator and, however, the terminal voltage is regulated by a homo-planar inductor alternator. In order to execute the computation of EMF and analyze the performance of HESG, 3-D FEM was utilized.

\section{Control Mechanism for WECSs}

Numerous control mechanisms are employed in WECS, when designing a generator, it is important to consider the vital parameters such as aerodynamic efficacy, statistical wind distribution, and control system, since these decisive factors can be used in performance evaluation. A study considered high overload capacity generators for this specific application. It was concluded that the optimization of generator is a must to diminish the losses and achieve the highest overload capability. The wind power generation systems act to achieve the sole aim of harnessing the maximum amount of wind energy and consequently converting it to electrical energy. One can achieve this easily through the help of a control structure which allows the operation range as well as the ideal algorithm of stable system with MPPT (Maximum Power Point Tracking). The objective of MPPT presents the harnessing of maximum energy by making few changes in operating point of the system in order to tap the full energy from wind. A control structure was proposed [147] (2013) with specific reference of wind energy systems on the bases of PMSG. With the purpose of enhancing the reliability and the robustness, the study determined the optimum structure using speed and torque control. This retrieved from the analysis of conventional control structures, which used variable speed, and fixed pitch wind energy generation systems [147].

The time-stepping FEA was offered (2006) [148] pertaining to a variable speed synchronous generator in addition to the rectifier. The bi-directional alternator speeds are maintained by this model, the application is a linear generator in terms of the ocean wave energy conversion [148].

In the study conducted in 2014 [149], the authors described the output power fluctuations faced in a wind farm and the relevant problems created in the power system. The study compared the fluctuations that occurred in the output power of conventional schemes with the proposed methods. However, this study's proposed scheme had the tracking of optimal rotational speed in such a manner that the output power was smoothened. A fuzzy PID controller used instead of traditional vector control, which resulted in the tracking of the turbine's optimal rotational speed and the smoothening of wind farm's output power [149].

In 2009, [150] presented a system design model and its control approaches for a 2 MW direct-driven PMSG fed through parallel-connected full power back-to-back PWM converters. Both the electromagnetic FE analysis as well as the optimal generator design was executed in this application in terms of wind generation [150].

An elaborate design and an experimental approach proposed in 2010 [151] for a completely passive wind turbine system without the active electronic part (power and control). The efficiency of the devices predominantly relied upon the condition where the system's design parameters were reciprocally adapted using an integrated optimal design methodology. This methodology ensures simultaneous optimization of wind power extraction and losses because of the global system in a specific wind speed 
profile. This way, the weight of the wind turbine generator was decreased. Based on the approaches discussed in earlier studies, optimal PMSG was obtain for critical features of passive wind turbines like geometric and energetic features [151]. Figure 19 illustrates the general representation of a typical variable-speed direct-driven PMSG wind turbine connected to the grid distribution.

The study conducted by [152] developed a holistic modelling of direct-driven PMSG-based grid-connected wind turbines in addition to control schemes for the interface converters. There were two distinguishable control schemes designed in this configuration for generator and grid-side converters.

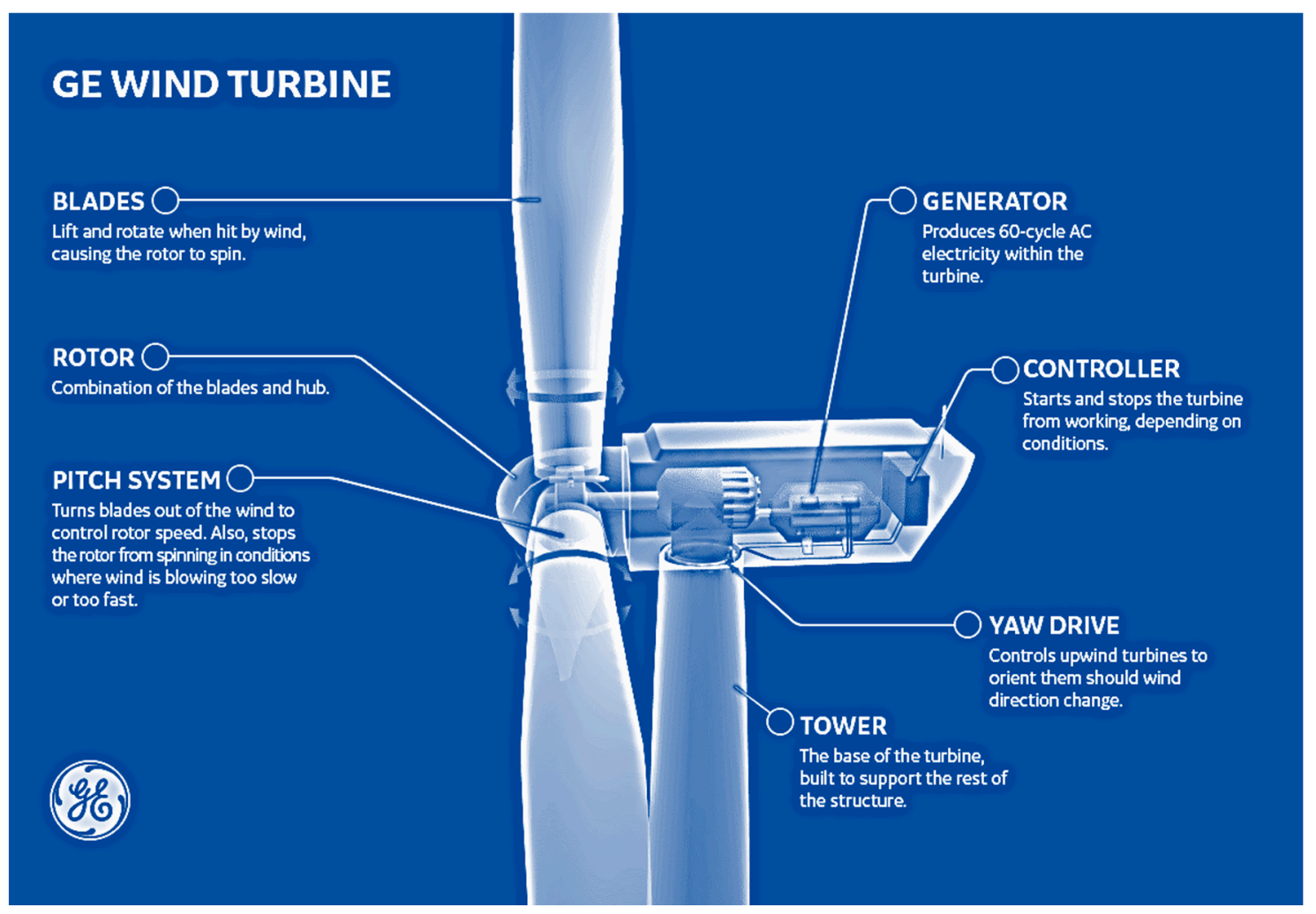

Figure 19. Typical variable-speed direct-driven PMSG wind turbine. Source: GE [153]

\section{Conclusions}

This review article developed a conceptual framework with an overview of research challenges, using which the proposed work of analysis, suitability, design, and control of PMSGs for Wind Energy Conversion Systems (WECS) to be carried out in future needs and development in the wind sector. The predicted influence and the preliminary results will further the progress beyond the threshold level set by the state-of-the-art envisioned research. In the literature, the WECSs and its classification as per wind turbine and generator schemes, the types of PMSG technologies where discussed elaborately. In addition, the study also suggested the solution found for optimization problems using the field computation technique. This study related to WECS development provided an advanced inter-disciplinary approach on technical parts, and compared with the pros cons of as previous studies. Information provided in this article can also be helpful in improving the WECS. It also reviewed the soft computing (SC) techniques that where applied for the optimal design methodologies of the PMSGs. When exploring the literature, unraveled mysteries and unexplored areas from the developmental perspective to take forward in future.

Author Contributions: All authors involved equally, and intensively investigated to produce the comprehensive research survey article in current form for renewable energy system for Wind Energy and its machine dynamics.

Funding: This research received no external funding.

Conflicts of Interest: The authors declare no conflict of interest. 


\section{References}

1. Şahin, A.D. Progress and recent trends in wind energy. Prog. Energy Combust. Sci. 2004, 30, 501-543. [CrossRef]

2. Padmanathan, K.; Govindarajan, U.; Ramachandaramurthy, V.K.; Rajagopalan, A.; Pachaivannan, N.; Sowmmiya, U.; Padmanaban, S.; Holm-Nielsen, J.B.; Xavier, S.; Periasamy, S.K. A Sociocultural Study on Solar Photovoltaic Energy System in India: Stratification and Policy Implication. J. Clean. Prod. 2019, 216, 461-481. [CrossRef]

3. Fatih, B.; Darbari, S. The Global Energy Outlook and the Increasing Role of India. In International Energy Agency Memorial Lecture; IEA: Paris, France, 29 August 2018.

4. Global Wind Energy Council (GWEC). Global Wind Report 2018; Global Wind Energy Council (GWEC): Brussels, Belgium, 2019.

5. Global Energy Transformation: A Roadmap to 2050 (2019 Edition); International Renewable Energy Agency (IRENA): Masdar City, UAE, 2019; ISBN 978-92-9260-121-8.

6. Michaelson, H.B. Techniques of Editorial Research in Electrical Engineering. J. Franklin Inst. 1949, 247, 245-253. [CrossRef]

7. Jianfeng, D.; Yi, T.; Jun, Y. Adaptive Gains Control Scheme for PMSG-Based Wind Power Plant to Provide Voltage Regulation Service. Energies J. 2019, 12, 753.

8. Ramakumar, R.; Slootweg, J.G.; Wozniak, L. Guest Editorial Introduction to the Special Issue on Wind Power. IEEE Trans. Energy Convers. 2007, 22, 1-3. [CrossRef]

9. Shafiullah, G.M.; Oo, A.M.; Ali, A.S.; Wolfs, P. Potential challenges of integrating large-scale wind energy into the power grid-A review. Renew. Sustain. Energy Rev. 2013, 20, 306-321. [CrossRef]

10. Global Wind Energy Council (GWEC). Global Wind Energy Outlook 2014; Global Wind Energy Council (GWEC): Brussels, Belgium, 2014.

11. Paulsen, U.S.; Vita, L.; Madsen, H.A.; Hattel, J.; Ritchie, E.; Leban, K.M.; Berthelsen, P.A.; Carstensen, S. 1st DeepWind 5 MW baseline design. Energy Procedia 2012, 24, 27-35. [CrossRef]

12. Global Wind Energy Council (GWEC). India Wind Energy Outlook 2012; Global Wind Energy Council (GWEC): Brussels, Belgium, 2012.

13. Mohanpurkar, M.; Ramakumar, R.G. Probability Density Functions for Power Output of Wind Electric Conversion Systems. In Proceedings of the IEEE PES General Meeting, Providence, RI, USA, 25-29 July 2010. [CrossRef]

14. Herbert, G.J.; Iniyan, S.; Sreevalsan, E.; Rajapandian, S. A review of wind energy technologies. Renew. Sustain. Energy Rev. 2007, 11, 1117-1145. [CrossRef]

15. Herbert, G.J.; Iniyan, S.; Amutha, D. A review of technical issues on the development of wind farms. Renew. Sustain. Energy Rev. 2014, 32, 619-641. [CrossRef]

16. Sareni, B.; Abdelli, A.; Roboam, X.; Tran, D.H. Model simplification and optimization of a passive wind turbine generator. Renew. Energy 2009, 34, 2640-2650. [CrossRef]

17. Islam, M.R.; Guo, Y.; Zhu, J. A review of offshore wind turbine nacelle: Technical challenges, and research and developmental trends. Renew. Sustain. Energy Rev. 2014, 33, 161-176. [CrossRef]

18. Zhong, D. Finite Element Analysis of Synchronous Machines. Ph.D. Thesis, The Pennsylvania State University, State College, PA, USA, May 2010.

19. Sethuraman, L.; Venugopal, V.; Zavvos, A.; Mueller, M. Structural integrity of a direct-drive generator for a floating wind turbine. Renew. Energy 2014, 63, 597-616. [CrossRef]

20. Chen, Z.; Blaabjerg, F. Wind farm-A power source in future power systems. Renew. Sustain. Energy Rev. 2009, 13, 1288-1300. [CrossRef]

21. Domínguez-García, J.L.; Gomis-Bellmunt, O.; Bianchi, F.D.; Sumper, A. Power oscillation damping supported by wind power: A review. Renew. Sustain. Energy Rev. 2012, 16, 4994-5006. [CrossRef]

22. Boldea, I. The Electric Generators Hand Book-Synchronous Generators; CRC Press, Taylor \& Francis Group: Boca Raton, FL, USA, 2006.

23. Nerg, J.; Ruuskanen, V. Lumped-parameter-based thermal analysis of a doubly radial forced-air-cooled direct-driven permanent magnet wind generator. Math. Comput. Simul. 2012, 90. [CrossRef]

24. Kumar, A.; Marwaha, S.; Singh, A.; Marwaha, A. Performance investigation of a permanent magnet generator. Simul. Model. Pract. Theory 2009, 17, 1548-1554. [CrossRef] 
25. Li, H.; Chen, Z. Design optimization and site matching of direct-drive permanent magnet wind power generator systems. Renew. Energy 2009, 34, 1175-1184. [CrossRef]

26. Aleksashkin, A.; Mikkola, A. Literature review on Permanent Magnet Generators Design and Dynamic Behavior; Lappenranta University of Technology: Lappeenranta, Finland, 2008; ISBN 978-952-214-708-0.

27. Gündoğdu, T.; Kömürgöz, G. Technological and economical analysis of salient pole and permanent magnet synchronous machines designed for wind turbines. J. Magn. Magn. Mater. 2012, 324, 2679-2686. [CrossRef]

28. Muetze, A. Deterministic global optimization of electromechanical energy converters. IEEE Ind. Appl. Mag. 2008, 14.

29. Kömürgöz, G.; Gündogdu, T. Comparison of Salient Pole and Permanent Magnet Synchronous Machines Designed for Wind Turbines. In Proceedings of the 2012 IEEE Power Electronics and Machines in Wind Applications, Denver, CO, USA, 16-18 July 2012.

30. Li, H.; Chen, Z. Design Optimization and valuation of Different Wind Generator Systems. In Proceedings of the 2008 International Conference on Electrical Machines and Systems, Wuhan, China, 17-20 October 2008; pp. 2396-2401.

31. Li, H.; Chen, Z. Overview of different wind generator systems and their comparisons. IET Renew. Power Gener. 2008, 2, 123-138. [CrossRef]

32. Li, H.; Chen, Z.; Polinder, H. Optimization of Multibrid Permanent-Magnet Wind Generator Systems. IEEE Trans. Energy Convers. 2009, 24, 82-92. [CrossRef]

33. Eriksson, S.; Bernhoff, H. Loss evaluation and design optimisation for direct driven permanent magnet synchronous generators for wind power. Appl. Energy 2011, 88, 265-271. [CrossRef]

34. Alnasir, Z.; Kazerani, M. An analytical literature review of stand-alone wind energy conversion systems from generator viewpoint. Renew. Sustain. Energy Rev. 2013, 28, 597-615. [CrossRef]

35. Rossa, R.; Król, E. Finite Element Analysis -Based Calculation of Load Characteristics of Stand-Alone PM Generators with Inner or Outer Rotor Constructions. In Proceedings of the XIX International Conference on Electrical Machines-ICEM 2010, Rome, Italy, 6-8 September 2010.

36. Park, Y.S.; Jang, S.M.; Choi, J.Y.; Choi, J.H.; You, D.J. Influence of AC-DC-DC Converter on Radial/Axial Flux Permanent Magnet Wind Power Generators with Mechanical Energy Storage System. In Proceedings of the 2013 IEEE International Conference on Industrial Technology (ICIT), Cape Town, South Africa, 25-28 February 2013.

37. Tapia, J.A.; Pyrhonen, J.; Puranen, J.; Lindh, P.; Nyman, S. Optimal Design of Large Permanent Magnet Synchronous Generators. IEEE Trans. Magn. 2013, 49, 642-650. [CrossRef]

38. Park, J.; Kim, J.; Shin, Y.; Lee, J.; Park, J. 3 MW class offshore wind turbine development. Curr. Appl. Phys. 2010, 10, S307-S310. [CrossRef]

39. Fei, W. Permanent Magnet Synchronous Machines with Fractional Slot and Concentrated Winding Configurations. Power and Drive Systems Group. Ph.D. Thesis, Cranfield University, Cranfield, UK, January 2011.

40. Ko, K.J.; Jang, S.M.; Park, J.H.; Cho, H.W.; You, D.J. Electromagnetic Performance Analysis of Wind Power Generator with Outer Permanent Magnet Rotor Based on Turbine Characteristics Variation Over Nominal Wind Speed. IEEE Trans. Magn. 2011, 47, 3292-3295. [CrossRef]

41. Duan, Y. Method for Design and Optimization of Surface Mount Permanent Magnet Machines and Induction Machines. Ph.D. Thesis, Georgia Institute of Technology, Atlanta, GA, USA, December 2010.

42. Stamenkovic, I.; Milivojevic, N.; Schofield, N.; Krishnamurthy, M. Emadi, A. Design, Analysis, and Optimization of Ironless Stator Permanent Magnet Machines. IEEE Trans. Power Electron. 2013, 28, 2527-2538. [CrossRef]

43. Antipov, V.N.; Danilevich, Y.B. Analysis and Investigation of Size Spectrum of Synchronous Machines Operating as Wind-Power-Generators in the Range of Rotation Frequencies of 75-300 rpm. Russ. Electr. Eng. 2009, 80, 23-28. [CrossRef]

44. Simion, S.V.A.; Livadaru, L.; Irimia, N.D.; Lazăr, F. FEM Analysis of a Low Speed Permanent Magnet Synchronous Machine with External Rotor for a Wind Generator. In Proceedings of the 2012 13th International Conference on Optimization of Electrical and Electronic Equipment (OPTIM), Brasov, Romania, 24-26 May 2012.

45. Colli, V.D.; Marignetti, F.; Attaianese, C. Analytical and Multiphysics Approach to the Optimal Design of a 10-MW DFIG for Direct-Drive Wind Turbines. IEEE Trans. Ind. Electr. 2012, 59, 2791-2799. [CrossRef] 
46. Guo, Z.; Chang, L. FEM Study on Permanent Magnet Synchronous Generators for Small Wind Turbines. In Proceedings of the Canadian Conference on Electrical and Computer Engineering, Saskatoon, SK, CA, 1-4 May 2005; pp. 641-644.

47. Hosseini, S.M.; Agha-Mirsalim, M.; Mirzaei, M. Design, Prototyping, and Analysis of a Low Cost Axial-Flux Coreless Permanent-Magnet Generator. IEEE Trans. Magn. 2008, 44, 75-80. [CrossRef]

48. Pinilla, M. Performance Improvement in a Renewable Energy Direct Drive Permanent Magnet Machine by means of Soft Magnetic Composite Interpoles. IEEE Trans. Energy Convers. 2012, 27, 440-448. [CrossRef]

49. Stegmann, J.A.; Kamper, M.J. Design Aspects of Double-Sided Rotor Radial Flux Air-Cored Permanent-Magnet Wind Generator. IEEE Trans. Ind. Appl. 2011, 47, 767-778. [CrossRef]

50. Park, Y.S.; Jang, S.M.; Choi, J.H.; Choi, J.Y.; You, D.J. Characteristic Analysis on Axial Flux Permanent Magnet Synchronous Generator Considering Wind Turbine Characteristics According to Wind Speed for Small-Scale Power Application. IEEE Trans. Magn. 2012, 48, 2937-2940. [CrossRef]

51. Chebak, A.; Viarouge, P.; Cros, J. Optimal design of a high-speed slotless permanent magnet synchronous generator with soft magnetic composite stator yoke and rectifier load. Math. Comput. Simul. 2010, 81, 239-251. [CrossRef]

52. Spooner, E.; Williamson, A.C.; Catto, G. Modular Design of Permanent Magnet Generator for Wind Turbines. IEE Proc.-Electr. Power Appl. 1996, 143, 388-395. [CrossRef]

53. Chan, T.F.; Lai, L.L. An Axial-Flux Permanent-Magnet Synchronous Generator for a Direct-Coupled Wind-Turbine System. IEEE Trans. Energy Convers. 2007, 22, 86-94. [CrossRef]

54. Caricchi, F.; Maradei, F.; De Donato, G.; Capponi, F.G. Axial-Flux Permanent-Magnet Generator for Induction Heating Gensets. IEEE Trans. Ind. Electron. 2010, 57, 128-137. [CrossRef]

55. Hanselman, D.C. Brushless PM Motor Design; Marcel Dekker: New York, NY, USA, 1997.

56. Hendershot, J.R.; Miller, T.J.; Miller, E. Design of Brushless Permanent Magnet Motor; Oxford University Press: Oxford, UK, 1994.

57. User's Guide of Maxwell 3D; ANSYS Inc.: Canonsburg, PA, USA, 2010.

58. Traxler-Samek, G.; Zickermann, R.; Schwery, A. Cooling Airflow, Losses, and Temperatures in Large Air-Cooled Synchronous Machines. IEEE Trans. Ind. Electron. 2010, 57, 172-180. [CrossRef]

59. Huang, Y.; Dong, J.; Jin, L.; Zhu, J.; Guo, Y. Eddy-Current Loss Prediction in the Rotor Magnets of a Permanent Magnet Synchronous Generator with Modular Winding Feeding a Rectifier Load. IEEE Trans. Magn. 2011, 47, 4203-4206. [CrossRef]

60. Spooner, E.; Williamson, A.C. Parasitic Losses in Modular Permanent-Magnet Generators. IEE Proc. Electr. Power Appl. 1997. [CrossRef]

61. Martin, F.; Zaïm, M.E.H.; Tounzi, A.; Bernard, N. Improved Analytical Determination of Eddy Current Losses in Surface Mounted Permanent Magnets of Synchronous Machine. IEEE Trans. Magn. 2014, 50, 1-9. [CrossRef]

62. Ruschetti, C.; Verucchi, C.; Bossio, G.; De Angelo, C.; García, G. Rotor demagnetization effects on permanent magnet synchronous machines. Energy Convers. Manag. 2013, 74, 1-8. [CrossRef]

63. Rodrigues, R.B.; Mendes, V.M.F.; Catalão, J.P.D.S. Protection of interconnected wind turbines against lightning effects: Over voltages and electromagnetic transients study. Renew. Energy 2012, 46, 232-240. [CrossRef]

64. Jin, Y. Fault Analysis and Protection for Wind Power Generation Systems. Ph.D. Thesis, University of Glasgow, Glasgow, UK, March 2011. Available online: http://theses.gla.ac.uk (accessed on 18 May 2015).

65. Kalokiris, G.K.; Kladas, A.G.; Hatzilau, I.K.; Cofinas, S.; Gyparis, I.K. Advances in magnetic materials and their impact on electric machine design. J. Mater. Process. Technol. 2007, 181, 148-152. [CrossRef]

66. Jung, J.W.; Lee, B.H.; Kim, D.J.; Hong, J.P.; Kim, J.Y.; Jeon, S.M.; Song, D.H. Mechanical Stress Reduction of Rotor Core of Interior Permanent Magnet Synchronous Motor. IEEE Trans. Magn. 2012, 48, 911-914. [CrossRef]

67. Geng, H.; Xu, D. Stability Analysis and Improvements for Variable-Speed Multipole Permanent Magnet Synchronous Generator-Based Wind Energy Conversion System. IEEE Trans. Sustain. Energy 2011, 2, 459-467. [CrossRef]

68. Xia, S.; Zhang, Q.; Hussain, S.; Hong, B.; Zou, W. Impacts of Integration of Wind Farms on Power System Transient Stability. Appl. Sci. 2018, 8, 1289. [CrossRef]

69. Frank, N.W.; Pakdelian, S.; Toliyat, H.A. Passive Suppression of Transient Oscillations in the Concentric Planetary Magnetic Gear. IEEE Trans. Energy Convers. 2011, 26, 933-939. [CrossRef] 
70. Westlake, A.J.G.; Bumby, J.R.; Spooner, E. Damping the power-angle oscillations of a permanent-magnet synchronous generator with particular reference to wind turbine applications. IEE Proc. Electr. Power Appl. 1996, 143, 269-280. [CrossRef]

71. Klontz, K.W.; Miller, T.J.; McGilp, M.I.; Karmaker, H.; Zhong, P. Short-Circuit Analysis of Permanent- Magnet Generators. IEEE Trans. Appl. 2011, 47, 1670-1680. [CrossRef]

72. Alshibani, S.; Agelidis, V.G.; Dutta, R. Lifetime Cost Assessment of Permanent Magnet Synchronous Generators for MW Level Wind Turbines. IEEE Trans. Sustain. Energy 2014, 5, 10-17. [CrossRef]

73. Giurgea, S.; Zire, H.S.; Miraoui, A. Two-Stage Surrogate Model for Finite-Element-Based Optimization of Permanent-Magnet Synchronous Motor. IEEE Trans. Magn. 2007, 43, 3607-3613. [CrossRef]

74. Kumar, A.; Marwaha, S.; Singh, A.; Marwaha, A. Comparative leakage field analysis of electromagnetic devices using finite element and fuzzy methods. Expert Syst. Appl. 2010, 37, 3827-3834. [CrossRef]

75. Roy, R.; Hinduja, S.; Teti, R. Recent advances in engineering design optimisation: Challenges and future trends. CIRP Ann. Manuf. Technol. 2008, 57, 697-715. [CrossRef]

76. Tsekouras, G.; Kiartzis, S.; Kladas, A.G.; Tegopoulos, J.A. Neural Network Approach Compared to Sensitivity Analysis Based on Finite Element Technique for Optimization of Permanent Magnet Generators. IEEE Trans. Magn. 2001, 37, 3618-3621. [CrossRef]

77. Pinilla, M.; Martinez, S. Optimal design of permanent-magnet direct-drive generator for wind energy considering the cost uncertainty in raw materials. Renew. Energy 2012, 41, 267-276. [CrossRef]

78. Fontchastagner, J.; Messine, F.; Lefèvre, Y. Design of Electrical Rotating Machines by Associating Deterministic Global Optimization Algorithm with Combinatorial Analytical and Numerical Models. IEEE Trans. Magn. 2007, 43, 3411-3419. [CrossRef]

79. Liu, C.; Chau, K.T.; Jiang, J.Z.; Jian, L. Design of a New Outer-Rotor Permanent Magnet Hybrid Machine for Wind Power Generation. IEEE Trans. Magn. 2008, 44, 1494-1497.

80. Leung, Y.W.; Wang, Y. An Orthogonal Genetic Algorithm with Quantization for Global Numerical Optimization. IEEE Trans. Evolut. Comput. 2001, 5, 41-53. [CrossRef]

81. Kicinger, R.; Arciszewski, T.; De Jong, K. Evolutionary computation and structural design: A survey of the state-of-the-art. Comput. Struct. 2005, 83, 1943-1978. [CrossRef]

82. Saridakis, K.M.; Dentsoras, A.J. Soft computing in engineering design-A review. Adv. Eng. Inform. 2008, 22, 202-221. [CrossRef]

83. Yusup, N.; Zain, A.M.; Hashim, S.Z.M. Evolutionary techniques in optimizing machining parameters: Review and recent applications (2007-2011). Expert Syst. Appl. 2012, 39, 9909-9927. [CrossRef]

84. Zhong, W.; Liu, J.; Xue, M.; Jiao, L. A Multiagent Genetic Algorithm for Global Numerical Optimization. IEEE Trans. Syst. Cybern. Part B Cybern. 2004, 34, 1128-1141. [CrossRef]

85. Rahnamayan, S.; Tizhoosh, H.R.; Salama, M.M. Opposition versus randomness in soft computing techniques. Appl. Soft Comput. 2008, 8, 906-918. [CrossRef]

86. Banos, R.; Manzano-Agugliaro, F.; Montoya, F.G.; Gil, C.; Alcayde, A.; Gómez, J. Optimization methods applied to renewable and sustainable energy: A review. Renew. Sustain. Energy Rev. 2011, 15, 1753-1766. [CrossRef]

87. Ahn, Y.; Park, J.; Lee, C.G.; Kim, J.W.; Jung, S.Y. Novel Memetic Algorithm implemented With GA (Genetic Algorithm) and MADS (Mesh Adaptive Direct Search) for Optimal Design of Electromagnetic System. IEEE Trans. Magn. 2010, 46, 1982-1985. [CrossRef]

88. Mukherjee, I.; Ray, P.K. A review of optimization techniques in metal cutting processes. Comput. Ind. Eng. J. 2006, 50, 15-34. [CrossRef]

89. Dennis, B.H.; Dulikravich, G.S. Optimization of magneto-hydrodynamic control of diffuser flows using micro-genetic algorithms and least-squares finite elements. Finite Elem. Anal. Des. 2001, 37, 349-363. [CrossRef]

90. Padmanathan, K.; Uma, G.; Vigna, K.R.; Sudar, O.S.T. Multiple Criteria Decision Making (MCDM) Based Economic Analysis of Solar PV System with Respect to Performance Investigation for Indian Market'. Sustainability J. 2017, 9, 820 .

91. Dias, A.H.F.; de Vasconcelos, J.A. Multiobjective genetic algorithms applied to solve optimization problems. IEEE Trans. Magn. 2002, 38, 1133-1136. [CrossRef]

92. Kiartzis, S.; Kladas, A. Deterministic and artificial intelligence approaches in optimizing permanent magnet generators for wind power applications. J. Mater. Process. Technol. 2001, 108, 232-236. [CrossRef] 
93. Das, S.; Abraham, A.; Konar, A. Particle Swarm Optimization and Differential Evolution Algorithms: Technical Analysis, Applications and Hybridization Perspectives. In Advances of Computational Intelligence in Industrial Systems. Studies in Computational Intelligence; Springer: Berlin/Heidelberg, Germany, 2008; Volume 116, pp. 1-38.

94. Bi, X.; Wang, Y. An Improved Artificial Bee Colony Algorithm. In Proceedings of the 2011 IEEE Computer Research and Development (ICCRD), Shanghai, China, 11-13 March 2011.

95. Babayigit, B.; Ozdemir, R. A modified artificial bee colony algorithm for numerical function optimization. In Proceedings of the 2012 IEEE Symposium on Computers and Communications (ISCC), Cappadocia, Turkey, 1-4 July 2012; pp. 245-249.

96. Rostami, N.; Feyzi, M.R.; Pyrhonen, J.; Parviainen, A.; Behjat, V. Genetic Algorithm Approach for Improved Design of a Variable Speed Axial-Flux Permanent-Magnet Synchronous Generator. IEEE Trans. Magn. 2012, 48, 4860-4865. [CrossRef]

97. Song, C.; Ye, J.; Liu, D.; Kang, Q. Receding Horizon Control of Fuzzy Systems Based on Numerical Optimization Algorithm. IEEE Trans. Fuzzy Syst. 2009, 17, 1336-1352. [CrossRef]

98. Chaturvedi, D.K. Soft Computing Techniques and Its Applications in Electrical Engineering; Springer: Berlin/Heidelberg, Germany, 2008.

99. Peng, F.; Tang, K.; Chen, G.; Yao, X. Population-Based Algorithm Portfolios for Numerical Optimization. IEEE Trans. Evolut. Comput. 2010, 14, 782-800. [CrossRef]

100. Bastos Filho, C.J.; de Lima Neto, F.B.; Lins, A.J.; Nascimento, A.I.; Lima, M.P. A Novel Search Algorithm based on Fish School Behavior. In Proceedings of the 2008 IEEE International Conference on Systems, Man and Cybernetics (SMC 2008), Suntec, Singapore, 12-15 October 2008; pp. 2646-2651.

101. Ho, S.L.; Yang, S.; Ni, G.; Wong, H.C.C. A Particle Swarm Optimization Method with Enhanced Global Search Ability for Design Optimizations of Electromagnetic Devices. IEEE Trans. Magn. 2006, 42, 1107-1110. [CrossRef]

102. Matić, D.; Kulić, F.; Pineda-Sánchez, M.; Kamenko, I. Support vector machine classifier for diagnosis in electrical machines: Application to broken bar. Expert Syst. Appl. 2012, 39, 8681-8689. [CrossRef]

103. Ho, S.L.; Yang, S.; Ni, G.; Wong, H.C.C. A Tabu Method to Find the Pareto Solutions of Multiobjective Optimal Design Problems in Electromagnetics. IEEE Trans. Magn. 2002, 38, 1013-1016. [CrossRef]

104. Wadhwa, R.S.; Lien, T. Electromagnet Shape Optimization using Improved Discrete Particle Swarm Optimization (IDPSO). In Proceedings of the 2011 COMSOL Conference, Stuttgart, Germany, 26-28 October 2011.

105. Arkadan, A.A.; Mneimneh, M.; Al-Aawar, N. R-FL-C Model for Design Optimizationof PM Generators. IEEE Trans. Magn. 2007, 43, 1649-1652. [CrossRef]

106. Li, G.; Niu, P.; Xiao, X. Development and investigation of efficient artificial bee colony algorithm for numerical function optimization. Appl. Soft Comput. 2012, 12, 320-332. [CrossRef]

107. Hahn, I. Heuristic Structural Optimization of the Permanent Magnets Used in a Surface Mounted Permanent-Magnet Synchronous Machine. IEEE Trans. Magn. 2012, 48, 118-127. [CrossRef]

108. Sha, H.; Mei, F.; Zhang, C.; Pan, Y.; Zheng, J. Identification Method for Voltage Sags Based on K-means-Singular Value Decomposition and Least Squares Support Vector Machine. Energies 2019, 12, 1137. [CrossRef]

109. Ho, S.L.; Yang, S.; Ni, G.; Wong, H.C.C. An Improved Tabu Search for the Global Optimizations of Electromagnetic Devices. IEEE Trans. Magn. 2001, 37, 3570-3574. [CrossRef]

110. Liu, L.; Liu, W.; Cartes, D.A. Particle swarm optimization-based parameter identification applied to permanent magnet synchronous motors. Eng. Appl. Artif. Intell. 2008, 21, 1092-1100. [CrossRef]

111. Yang, S.; Machado, J.M.; Ni, G.; Ho, S.L.; Zhou, P. A Self-Learning Simulated Annealing Algorithm for Global Optimizations of Electromagnetic Devices. IEEE Trans. Magn. 2000, 36, 1004-1008.

112. Sudhoff, S.D.; Cale, J.; Cassimere, B.; Swinney, M. Genetic Algorithm Based Design of a Permanent Magnet Synchronous Machine. In Proceedings of the IEEE International Conference on Electric Machines and Drives, 2015, San Antonio, TX, USA, 15 May 2005.

113. Ho, S.L.; Yang, S.; Wong, H.C.C.; Cheng, K.W.E.; Ni, G. An Improved Ant Colony Optimization Algorithm and Its Application to Electromagnetic Devices Designs. IEEE Trans. Magn. 2005, 41, 1764-2004. [CrossRef]

114. Karaboga, D.; Basturk, B. A powerful and efficient algorithm for numerical function optimization: artificial bee colony (ABC) algorithm. J. Glob. Optim. 2007, 39, 459-471. [CrossRef] 
115. Karaboga, D.; Basturk, B. A comparative study of Artificial Bee Colony algorithm. Appl. Math. Comput. 2009, 214, 108-132. [CrossRef]

116. Hasanien, H.M.; Muyeen, S.M. Design Optimization of Controller Parameters Used in Variable Speed Wind Energy Conversion System by Genetic Algorithms. IEEE Trans. Sustain. Energy 2012, 3, 200-207. [CrossRef]

117. Ho, S.L.; Yang, S.; Wong, H.C.C.; Ni, G. A Meshless Collocation Method Based on Radial Basis Functions and Wavelets. IEEE Trans. Magn. 2004, 40, 1021-1024. [CrossRef]

118. Im, C.H.; Jung, H.K.; Kim, Y.J. Hybrid Genetic Algorithm for Electromagnetic Topology Optimization. IEEE Trans. Magn. 2003, 39, 2163-2169.

119. Potgieter, J.H.; Kamper, M.J. Design of New Concept Direct Grid-Connected Slip-Synchronous Permanent-Magnet Wind Generator. IEEE Trans. Ind. Appl. 2012, 48, 913-922. [CrossRef]

120. Chen, Y.; Wang, D. FEM Analysis of Surface-Inserted Permanent Magnets Synchronous Generator. In Proceedings of the 2011 International Conference on Electrical and Control Engineering, Yichang, China, 16-18 September 2011; pp. 665-668.

121. Ailam, E.H.; Netter, D.; Leveque, J.; Douine, B.; Masson, P.J.; Rezzoug, A. Design and Testing of a Superconducting Rotating Machine. IEEE Trans. Appl. Supercond. 2007, 17, 27-33. [CrossRef]

122. Widyan, M.S.; Hanitsch, R.E. High-power density radial-flux permanent-magnet sinusoidal three-phase three-slot four-pole electrical generator. Electr. Power Energy Syst. 2012, 43, 1221-1227. [CrossRef]

123. Farooqui, S.Z. Conversion of squirrel cage induction motors to wind turbine PMG. Renew. Energy 2012, 41, 345-349. [CrossRef]

124. Subiabre, E.E.; Mueller, M.A. Efficiency Estimation of an Air-Cored Permanent Magnet Synchronous Generator Using Finite Elements and Equivalent Circuit Modelling. In Proceedings of the 2011 IEEE International Electric Machines \& Drives Conference (IEMDC), Niagara Falls, ON, CA, 16-18 September 2011; pp. 377-382.

125. Alshibani, S.; Dutta, R.; Agelidis, V.G. An Investigation of the Use of a Halbach Array in MW Level Permanent Magnet Synchronous Generators. In Proceedings of the 2012 XX International Conference on Electrical Machines, Marseille, France, 2-5 September 2012; pp. 59-65, ISBN 978-1-4673-0142-8. [CrossRef]

126. Choi, J.S.; Yoo, J. Design of a Halbach Magnet Array Based on Optimization Techniques. IEEE Trans. Magn. 2008, 44, 2361-2366. [CrossRef]

127. Danielsson, O.; Leijon, M.; Sjostedt, E. Detailed Study of the Magnetic Circuit in a Longitudinal Flux Permanent-Magnet Synchronous Linear Generator. IEEE Trans. Magn. 2005, 41, 2490-2495. [CrossRef]

128. Brisset, S.; Vizireanu, D.; Brochet, P. Design and Optimization of a Nine-Phase Axial-Flux PM Synchronous Generator With Concentrated Winding for Direct-Drive Wind Turbine. IEEE Trans. Ind. Appl. 2008, 44, 707-715. [CrossRef]

129. Legranger, J.; Friedrich, G.; Vivier, S.; Mipo, J.C. Combination of Finite-Element and Analytical Models in the Optimal Multi domain Design of Machines: Application to an Interior Permanent-Magnet Starter Generator. IEEE Trans. Ind. Appl. 2010, 46, 232-239. [CrossRef]

130. Potgieter, J.H.; Kamper, M.J. Optimum Design and Technology Evaluation of Slip Permanent Magnet Generators for Wind Energy Applications. In Proceedings of the 2012 IEEE Energy Conversion Congress and Exposition (ECCE), Raleigh, NC, USA, 15-20 September 2012; pp. 2342-2349.

131. Hsiao, C.; Yeh, S.; Hwang, J. Design of High Performance Permanent-Magnet Synchronous Wind Generators. Energies 2014, 7, 7105-7124. [CrossRef]

132. Jin, W.B.; Zhang, D.; An, Z.L.; Tan, R.Y. Analysis and Design of Hybrid Excitation Permanent Magnet Synchronous Generators. Front. Electr. Electron. Eng. China 2006, 1, 63-66. [CrossRef]

133. More, D.S.; Kalluru, H.; Fernandes, B.G. Design and analysis of full pitch winding and concentrated stator pole winding three-phase flux reversal machine for low speed application. Sādhanā 2008, 33, 671-687. [CrossRef]

134. More, D.S.; Fernandes, B.G. Power density improvement of three phase flux reversal machine with distributed winding. IET Electr. Power Appl. 2010, 4, 109-120. [CrossRef]

135. Zakharenko, A.B.; Semenchukov, G.A. Research on the Synchronous Electric Machine with a Rake of Permanent Magnets. Russ. Electr. Eng. 2007, 78, 100-105. [CrossRef]

136. Sun, X.; Cheng, M.; Hua, W.; Xu, L. Design of Double-Layer Permanent Magnet Dual Mechanical Port Machine for Wind Power Application. IEEE Trans. Magn. 2009, 45, 4613-4616. 
137. Zhang, S.; Tseng, K.J.; Nguyen, T.D. PMSG based Multi-Generator Architecture for Wind Generation Application. In Proceedings of the 2011 6th IEEE Conference on Industrial Electronics and Applications, Beijing, China, 21-23 June 2011; pp. 335-340.

138. Chan, T.F.; Wang, W.; Lai, L.L. Field in a Transverse- and Axial-Flux Permanent Magnet Synchronous Generator From 3-D Finite Element Analysis. IEEE Trans. Magn. 2012, 48, 1055-1058. [CrossRef]

139. Li, J.; Chau, K.T.; Jiang, J.Z.; Liu, C.; Li, W. A New Efficient Permanent-Magnet Vernier Machine for Wind Power Generation. IEEE Trans. Magn. 2010, 46, 1475-1478. [CrossRef]

140. Tapia, J.A.; Leonardi, F.; Lipo, T.A. Consequent-Pole Permanent-Magnet Machine with Extended Field-Weakening Capability. IEEE Trans. Ind. Appl. 2003, 39, 1704-1709. [CrossRef]

141. Tessarolo, A. Accurate Computation of Multiphase Synchronous Machine Inductances Based on Winding Function Theory. IEEE Trans. Energy Convers. 2012, 27, 895-904. [CrossRef]

142. Wang, W.; Cheng, K.W.E.; Ding, K.; Meng, L.C. A Novel Approach to the Analysis of the Axial-Flux Permanent-Magnet Generator with Coreless Stator Supplying a Rectifier Load. IEEE Trans. Magn. 2011, 47, 2391-2394. [CrossRef]

143. Fan, Y.; Chau, K.T.; Cheng, M. A New Three-Phase Doubly Salient Permanent Magnet Machine for Wind Power Generation. IEEE Trans. Ind. Appl. 2006, 42, 53-60.

144. Tiwari, R.; Padmanaban, S.; Neelakandan, R.B. Coordinated Control Strategies for a Permanent Magnet Synchronous Generator Based Wind Energy Conversion System. Energies 2017, 10, 1493. [CrossRef]

145. Lubin, T.; Hamiti, T.; Razik, H.; Rezzoug, A. Comparison Between Finite-Element Analysis and Winding Function Theory for Inductances and Torque Calculation of a Synchronous Reluctance Machine. IEEE Trans. Magn. 2007, 43, 3406-3410. [CrossRef]

146. Xinghe, F.; Jibin, Z. Numerical Analysis on the Magnetic Field of Hybrid Exciting Synchronous Generator. IEEE Trans. Magn. 2009, 45, 4590-4593. [CrossRef]

147. Carranza, O.; Figueres, E.; Garcerá, G.; Gonzalez-Medina, R. Analysis of the control structure of wind energy generation systems based on a permanent magnet synchronous generator. Appl. Energy 2013, 103, 522-538. [CrossRef]

148. Thorburn, K.; Karlsson, K.E.; Wolfbrandt, A.; Eriksson, M.; Leijon, M. Time stepping Finite Element Analysis of a variable speed synchronous generator with rectifier. Appl. Energy 2006, 83, 371-386. [CrossRef]

149. Varzaneh, S.G.; Gharehpetian, G.B.; Abedi, M. Output power smoothing of variable speed wind farms using rotor-inertia. Electric Power Syst. Res. 2014, 116, 208-217. [CrossRef]

150. Huang, K.; Zhang, Y.; Huang, S.; Lu, J.; Gao, J.; Cai, L. Some Practical Consideration of a 2MW Direct-drive Permanent-magnet Wind-power Generation System. In Proceedings of the 2009 International Conference on Energy and Environment Technology, Guilin, China, 16-18 October 2009; pp. 819-828.

151. Tran, D.H.; Sareni, B.; Roboam, X.; Espanet, C. Integrated Optimal Design of a Passive Wind Turbine System: An Experimental Validation. IEEE Trans. Sustain. Energy 2010, 1, 48-56. [CrossRef]

152. Alaboudy, A.H.K.; Daoud, A.A.; Desouky, S.S.; Salem, A.A. Converter controls and flicker study of PMSG-based grid connected wind turbines. Ain Shams Eng. J. 2012, 4, 75-91. [CrossRef]

153. Available online: https://www.ge.com/renewableenergy/wind-energy/onshore-wind/turbines (accessed on 14 June 2019).

(C) 2019 by the authors. Licensee MDPI, Basel, Switzerland. This article is an open access article distributed under the terms and conditions of the Creative Commons Attribution (CC BY) license (http://creativecommons.org/licenses/by/4.0/). 